\title{
MIGRAÇÃO E URBANIZAÇÃO NO BRASIL: PROCESSOS DE CONCENTRAÇÃO E DESCONCENTRAÇÃO ESPACIAL E O DEBATE RECENTE
}

\author{
Ralfo Matos ${ }^{1}$ \\ Rosana Baeninger ${ }^{2}$
}

\section{1- INTRODUÇÃO}

As migrações internas e a urbanização são dois grandes processos sociais que tanto dão sentido e forma às transformações estruturais deflagradas pelo avanço da modernidade capitalista no século XX no Brasil, quanto explicam em larga medida a ocupação do território nacional e as recentes manifestações de dispersão e redistribuição da população no território.

Esse trabalho procura examinar sinteticamente essa importante dimensão do desenvolvimento socioespacial contemporâneo do País, mediante revisão da literatura, exposição dos principais pontos do debate e apresentação de algumas das evidências mais recentes sobre o processo de redistribuição populacional no espaço, sobretudo o que abrange os últimos 30 anos.

Para tanto, a primeira parte do texto apresenta breves comentários sobre a fase histórica anterior de concentração demográfica e urbano-industrial. A partir desse pano de fundo, focaliza-se a etapa subsequente, quando começava a se esgotar essa tendência e emergir inéditos processos espaciais de desconcentração econômica. Nesse contexto, a discussão pautou-se sobre possíveis efeitos de processos concomitantes ou não de desconcentração/reconcentração econômica e redistribuição da população.

Em face disso, tornou-se necessária a reflexão apoiada em dados empíricos e em estudos recentes sobre o ritmo e intensidade da desaceleração do crescimento metropolitano, de modo a melhor visualizar a difusão de uma nova urbanização desconcentrada envolvendo,

\footnotetext{
${ }^{1}$ Professor e Pesquisador do Departamento de Geografia do Instituto de Geociências (IGC) da Universidade Federal de Minas Gerais

${ }^{2}$ Professora do Departamento de Sociologia. Instituto de Filosofia e Ciências Humanas e Pesquisador do Núcleo de Estudos de População -NEPO da Universidade Estadual de Campinas -UNICAMP.

Cadernos do Leste

Artigos Cientificos

Belo Horizonte, Edição Especial, 2000 a 2008
} 
inclusive, alterações nos sentidos e direções dos movimentos migratórios. A última parte desse estudo, portanto, analisa a redistribuição da população na atual rede urbana brasileira e o papel das aglomerações urbanas não-metropolitanas e das localidades não-primazes nos processos recentes de urbanização e reorganização da população no espaço.

\section{2- A CONCENTRAÇÃO DEMOGRÁFICA E URBANO-INDUSTRIAL NO PAÎ́S}

O processo de concentração urbano-industrial no Brasil pode ser visualizado a partir de etapas nas quais ele se define, expande e consolida-se, em uma cronologia que inicia-se em fins do século XIX indo até mais ou menos $1970^{3}$. Com base em Faria (1978), pode-se recortar a trajetória da urbanização brasileira nesse período em quatro momentos. O primeiro, abrangendo um período maior, de 1885 a 1929, sendo os subsequentes com durações menores: 1930-1955, 1956-1966 e 1967-1973.

No decorrer desses períodos, o País também experimentou fases distintas de desenvolvimento econômico, nas quais as migrações internas e internacionais participaram como um dos fundamentos da ocupação do espaço nacional ${ }^{4}$. De fato, a dinâmica da redistribuição espacial da população no espaço vincula-se, historicamente, às transformações estruturais pelas quais a sociedade brasileira passou, tendo como elementos básicos os processos migratórios e de urbanização.

As migrações internas no Brasil têm sido um fator chave da redistribuição da população no espaço desde o último quartel do século XIX, com o fim da escravidão (Balán, 1974). A transição para o trabalho assalariado, a contribuição qualitativa e quantitativa da imigração internacional, as transformações em curso na base produtiva, da virada do século até 1930, foram mudanças essenciais à estruturação territorial do Centro-Sul brasileiro (Cano,

\footnotetext{
${ }^{3}$ A respeito do processo de desenvolvimento econômico e urbanização no País, veja-se Cano (1977), Faria (1978), dentre outros.

${ }^{4}$ Destaca-se na bibliografia nacional os importantes estudos de Faria (1991), Balán (1974), Singer (1973), Lopes (1973), Lopes e Patarra (1975), Cano (1977), Graham e Hollanda (1980), dentre outros.

Cadernos do Leste

Artigos Cientificos

Belo Horizonte, Edição Especial, 2000 a 2008
} 
1977), fazendo inaugurar um processo urbano-industrial que iria conhecer grande intensidade nas décadas subsequentes (Lopes, 1973).

A partir dos anos de 1930, até meados da década de 50, os fluxos migratórios internos aceleraram-se e assumiram volumes e direções crescentemente a favor das regiões Sudeste, Sul e Centro-Oeste, como resultado da industrialização baseada no processo de substituição de importações; do incremento da urbanização, notadamente no eixo Rio/São Paulo (Faria, 1983, Cano, 1977); e da expansão da fronteira agrícola no Paraná, Mato Grosso/Goiás/Maranhão (Martine, 1987).

De toda a forma, até 1950, a rede urbana brasileira ainda era muito incipiente em termos de número e tamanho de cidades. A urbanização mais densa e dinâmica concentravase nos estados de São Paulo e Rio de Janeiro, onde o transporte rodoferroviário já começara a favorecer a formação e desenvolvimento de um sistema urbano interligado e integrado.

Esse quadro, entretanto, requalifica-se nos anos 50. Martine et al (1988) não deixam dúvidas sobre o dinamismo da urbanização resultante das altas taxas de crescimento vegetativo da própria população urbana e da impressionante contribuição das migrações internas de tipo campo-cidade. De fato, a taxa de crescimento do Brasil urbano entre 1950 e 1960 atingiu o ritmo inusitado de 5,3\% ao ano, refletindo a aceleração da urbanização e industrialização do período. Em 1950, apenas 36\% da população brasileira residia em áreas urbanas, em 1960 chegava a 45\%.

Com a década de 1960, a expansão da economia brasileira e os próprios efeitos inerciais do crescimento demográfico derivados da transição da mortalidade ${ }^{5}$ surgem vários núcleos de concentração urbana no País. Na verdade, o período 1967-1973, com o chamado 'milagre econômico', retrata uma nova etapa na relação 'urbanização-migração', em face da maturação do desenvolvimento urbano-industrial; momento em que a existência de um operariado crescentemente sindicalizado dá o tom às transformações na estrutura social e política que o País vivenciava.

\footnotetext{
${ }^{5}$ Os efeitos da expansão demográfica, derivados da queda da mortalidade, favoreceram o surgimento das "aglomerações urbanas" e o processo de interiorização da rede urbana, já que a população sobrevivente às enfermidades típicas do antigo Brasil rural, estava crescentemente vindo para as cidades, onde a disponibilidade de medicamentos e infraestrutura social se expandia.

Cadernos do Leste

Artigos Cientificos

Belo Horizonte, Edição Especial, 2000 a 2008
} 
Nessa etapa, as migrações internas, de curta ou longa distância, representavam uma forma de possibilidade efetiva de mobilidade social (Faria, 1991; Dedecca e Brandão, 1992; Martine e Peliano, 1976). Não obstante a existência de exclusão, marginalidade e pobreza no interior da população de baixa renda, o modelo de desenvolvimento econômico propiciava níveis expressivos de inserção de migrantes internos aos mercados de trabalho urbanos, sobretudo nas áreas mais dinâmicas do Sudeste, tornando bastante estreita a relação urbanização, migração e emprego.

A modernização industrial, alguns dos resultados do Plano de Metas (como a expansão rodoviária e a construção de Brasília), o início da modernização agrícola junto à ocupação de novas fronteiras de recursos ${ }^{6}$ acompanhavam esse dinamismo $^{7}$. Em 1970, pela primeira vez a população urbana ultrapassa a população rural, 52 milhões contra 41 milhões, respectivamente.

Nesse momento, quando começa também a ocorrer o esgotamento de algumas das áreas de fronteira agrícola, as novas trajetórias migratórias ${ }^{8}$ reforçam o padrão de concentração da população em cidades de tamanho cada vez maior (Martine, 1987). A expansão dos grandes centros urbanos ganhava nova expressão espacial com a emergência das configurações metropolitanas ${ }^{9}$.

Entretanto, visto por um outro ângulo, o antigo projeto de interiorização do desenvolvimento brasileiro parecia estar se tornando realidade desde, pelo menos, fins dos anos 60 e princípio da década de 70. Com as mudanças na estrutura produtiva, à época do chamado "milagre brasileiro", e a materialização de investimentos estratégicos, públicos e

\footnotetext{
${ }^{6}$ Prefigurada na corrida rumo ao Centro-Oeste e Amazônia, privilegiando setores como a pecuária e recursos minerais (Martine e Camargo, 1984).

${ }^{7}$ Cano (1985), estudando o movimento da indústria e a concentração regional entre 1930-1970, mostrou o forte aumento da concentração em São Paulo, quando a "periferia" nacional também exibia expansão industrial acelerada, embora a taxas bem inferiores às desse estado. Durante a chamada "industrialização restringida", São Paulo determinou a expansão, em forma e ritmo, pela consolidação da indústria pesada mais diversificada e mais dinâmica do País. Na periferia, ainda faltavam os efeitos de encadeamento, e uma expansão consistente dos mercados internos, sobretudo no tocante a bens intermediários e de capital

${ }^{8}$ Ver Brito (1997).

9 Não por acaso as regiões metropolitanas foram instituídas em 1973 pela Lei Complementar 9 do Governo Federal, afinal cerca de $70 \%$ das migrações internas na década de 70 destinaram-se as regiões metropolitanas.
}

Cadernos do Leste

Artigos Científicos

Belo Horizonte, Edição Especial, 2000 a 2008 
privados, iniciava-se um processo de descentralização econômica que se refletiria diretamente sobre a urbanização brasileira, fazendo expandir a rede urbana, tornando mais consistente o processo de interiorização do desenvolvimento (Negri, 1996).

Em resumo, a trajetória dos deslocamentos internos da população brasileira e a dinâmica da urbanização acelerada entre 1930 e 1980 sintetizam profundas transformações econômicas e sociais que marcaram a passagem de um mundo agrário para um mundo urbano. Como resultado surge um padrão de crescimento urbano intenso e concentrado nas áreas mais dinâmicas do Sudeste brasileiro, embora sinais eloquentes de desconcentração industrial tenham sido observados no decorrer dos anos $70{ }^{10}$

\section{3- O DEBATE SOBRE OS PROCESSOS RECENTES DE DESCONCENTRAÇÃO ESPACIAL, DESCENTRALIZAÇÃO ${ }^{11}$ ECONÔMICA E REDISTRIBUIÇÃO DA POPULAÇÃO URBANA. ${ }^{12}$}

O debate acerca da desconcentração econômica no Brasil é relativamente recente. ${ }^{13}$ Alguns estudos chegaram a deduzir que a concentração econômica baseada na expansão industrial no Estado de São Paulo perdia força e intensidade nos anos 70, o que apontava para uma situação inédita de desconcentração. Amarante e Bondioli (1987) concluíram que o Sudeste apresentou redução de participação na apropriação da renda regional entre 19751985, resultando em diminuição das diferenças regionais. Martine e Diniz (1989) mostraram

\footnotetext{
${ }^{10}$ Ver Cano (1995), Diniz (1995), Pacheco (1998) e Negri (1996), dentre outros.

${ }^{11}$ Descentralização e desconcentração não são conceitos idênticos. O primeiro pode referir-se ao ato de criar ou fortalecer pólos secundários mediante ações administrativas, políticas e econômicas, que, inclusive, não implicam necessariamente em relocalizações espaciais, nem abrangem a órbita da produção, estrito senso. Tais ações geralmente são conduzidas por diferentes esferas do poder público. O segundo conceito, embora similar ao primeiro, refere-se mais diretamente à novas localizações de assentamentos humanos e instalações produtivas derivadas da saída de atividades econômicas e populações de espaços centrais congestionados e de grande visibilidade histórica.

${ }^{12}$ Nesse estudo privilegia-se os autores brasileiros que focalizam a discussão da desconcentração econômica na ótica dos estudos urbanos e regionais.

13 A discussão sobre a descentralização de atividades em Países industrializados, ou com forte base industrial, é relativamente nova e as evidências desse processo são apontadas por diversos estudiosos nas últimas décadas, a exemplo de Greenwood (1980), Linn (1981), Katzmam (1986), Redwood (1988), Richardson (1980), Townroe e Ken (1984), entre outros. Katzmam, por exemplo, não tinha dúvidas em afirmar que, durante os anos 70, teria ocorrido "pela primeira vez, em todo o mundo, o fenômeno da reversão da polarização" (Katzman, 1986:196).
}

Cadernos do Leste

Artigos Cientificos

Belo Horizonte, Edição Especial, 2000 a 2008 
que, entre 1981 e 1988, a produção paulista na indústria de transformação evoluíra a taxas menores que a média nacional, da mesma forma que os dados sobre participação setorial no Produto Interno Bruto de São Paulo e regiões assinalavam o declínio da participação de São Paulo na agricultura e indústria entre 1970 e 1980, embora tenha se ampliado nos serviços.

Contudo, outros autores discutiam o alcance do fenômeno da desconcentração econômica arrolando argumentos de outra natureza. Azzoni (1986:124-5) perguntava se de fato havia uma tendência de descentralização econômica e espacial generalizada ou se, na verdade, tratar-se-ia apenas de um processo de acomodação das empresas a variações de custos locacionais devido a um crescimento urbano-industrial muito rápido, com amplitude espacial limitada. O autor, inclusive, chega a criticar tamanho de cidade como indicador de economias aglomerativas, aludindo ao conceito de economias de regionalização: "a região como um campo aglomerativo exercendo poder de atração sobre novos investimentos industriais". Nessa perspectiva, surgem cidades situadas dentro do campo aglomerativo que apresentam crescimento superior ao da própria cidade central, usufruindo um nível satisfatório de vantagens aglomerativas, sem a necessidade de cobrir os custos locacionais incorríveis na cidade grande, dado que num grande conglomerado urbano homogeneiza-se a oferta de serviços, transportes, comunicações, etc.

Haddad (1989), discutindo também a mesma questão, chegou a assinalar alguns pontos que punham em dúvida a tese da desconcentração. Dentre seus argumentos, vale destacar os relativos: às resistências inerciais que se oporiam a alterações do padrão locacional concentrador; às incertezas sobre a existência de condições suficientes para a sustentação de um crescimento acelerado nas periferias; às externalidades ainda atraentes nas áreas sob a influência da grande metrópole, especialmente se retomada a expansão econômica, quando então novos ciclos tecnológicos não poderiam dispensar o ambiente central.

Mesmo Martine e Diniz (1989) perguntavam se de fato houve uma perda da ascendência de São Paulo ou apenas ocorreu uma extensão natural da área de influência do polo. Além disso, não se sabia se a desconcentração persistiria no tempo ou se teria sido apenas uma manifestação típica dos anos 70, até como resposta aos investimentos estatais da época.

Cadernos do Leste

Artigos Cientificos

Belo Horizonte, Edição Especial, 2000 a 2008 
Azzoni (1986:124), conclui que: a) os movimentos industriais internos ao Estado de São Paulo se associariam "às variações nos custos e nas vantagens locacionais em cada área"; b) as empresas pesquisadas mostraram-se bastante solidárias à decisões emanadas das administrações centrais situadas no Core. As evidências indicariam que "longe de constituir-se um sinal de Reversão da Polarização, o fenômeno observado em São Paulo estaria mais próximo de um espraiamento da indústria dentro da área mais industrializada do País, em um processo do tipo desconcentração-concentrada". Seria, aproximadamente, um tipo de suburbanização das atividades industriais em âmbito mais abrangente.

Diniz (1993), entretanto, critica as opções metodológicas de Azzoni, arguindo que não se poderia ter tomado o Estado de São Paulo como parâmetro de comparação com o resto do Brasil, já que o grande "Core" do País, a grande concentração industrial estava sediada em sua área metropolitana. Além disso, Azzoni não observou que o espraiamento industrial extrapolava em muito o raio de seu campo aglomerativo (de aproximadamente $150 \mathrm{Km}$ ), alcançando uma ampla região que se estende por mais de $1.700 \mathrm{Km}$, indo do centro de Minas Gerais ao nordeste do Rio Grande do Sul. Segundo Diniz (1993) a desconcentração ocorria somente em espaços seletivos bem equipados e ricos em externalidades, cuja abrangência enfeixava as metrópoles de Belo Horizonte e Porto Alegre e partes expressivas do estado de São Paulo e estados do Sul, delineando o que se denomina "desenvolvimento poligonal".

Convém ressaltar que a industrialização brasileira conviveu com taxas de crescimento extremamente elevadas, notadamente nas décadas de 1950 e 1960, período em que os investimentos diversificaram-se (contando com a participação expressiva do capital estrangeiro) e convergiram para a indústria pesada paulista, como observa Cano (1985). A grande concentração industrial em São Paulo efetivara-se integrada, horizontal e verticalmente, favorecida pela concentração de renda e expansão do setor de bens duráveis à época do "milagre econômico".

Negri (2000), enfatiza a explicação dos determinantes da desconcentração industrial dos anos 70 e 80, associando-a às diversas obras, programas e políticas deflagradas pelos Governos Federal e Estadual a partir dos anos 70. O autor relaciona, por exemplo, as políticas de indução da desconcentração na órbita federal (notadamente as contidas no II Cadernos do Leste Artigos Cientificos 
PND) que, explicitamente, propunham várias metas voltadas ao desenvolvimento regional mediante incentivos fiscais, o que fez com que a periferia nacional se tornasse a maior receptora de novos investimentos no período.

A desconcentração econômica no espaço nacional certamente associa-se à ação interventora do Estado, embora os fracassos que acompanham tais ações sejam também notórios e conhecidos, alguns resultando em piora dos desequilíbrios regionais. Determinadas metas e investimentos públicos produziram, entretanto, impactos de curto e longo prazo, a exemplo do projeto de interiorização do desenvolvimento nacional expresso no Plano de Metas e no esforço de construção de Brasília ao final dos anos 50. Tais ações, geradoras de efeitos multiplicadores diversos, permitiram o incremento de novas áreas industriais que, inclusive, acompanharam o processo de metropolização que o País experimentava nos anos 60, da mesma forma que relacionaram-se à instalação de indústrias em espaços seletivos do interior do Estado de São Paulo. Note-se que o interior paulista, desde os anos 70, apresentava um expressivo incremento do sistema de transportes e circulação.

\section{4- DESECONOMIAS DE AGLOMERAÇÃO E DESMETROPOLIZAÇÃO}

$\mathrm{Na}$ discussão sobre desconcentração industrial é preciso que se considere as deseconomias de aglomeração presentes em grandes cidades, nas quais estão instaladas as principais indústrias de importância histórica. Da mesma forma, fatores "geoeconômicos" devem ser mapeados nessa discussão, mormente aqueles referentes à articulação interregional, que contribui para a difusão do desenvolvimento e dos efeitos de dispersão pelas redes urbanas. Para tanto é essencial contar com estruturas organizacionais dinâmicas envolvendo instituições e firmas distribuídas no espaço nacional - e com sistemas de transportes e comunicações que favoreçam a proliferação espacial não só de industrias, mas também das prestadoras de serviços acopladas à industrialização.

Redwood (1988), inspirado na análise do caso brasileiro, chegou a afirmar que a descentralização pode ocorrer se a população urbana nacional estiver muito concentrada em um ou dois grandes centros de Países com territórios extensos, mas abrigando um bom Cadernos do Leste 
número de cidades secundárias. O autor entendia que, no Brasil, a "despolarização" estaria ligada ao processo paralelo de descentralização industrial de São Paulo e Rio de Janeiro, vis-àvis o aumento da importância das metrópoles regionais e de outras cidades secundárias enquanto localizações econômicas alternativas. Para o autor, durante os anos 70 teria havido uma redução da polarização da metrópole paulista tanto no interior de São Paulo como no sistema urbano nacional, como a indicar o início de uma tendência de descentralização urbana e uma grande mudança nos padrões de distribuição populacional. Ao analisar a rede de cidades do Brasil, através de dados de população e de localização industrial, concluía que teria havido desconcentração das principais áreas metropolitanas brasileiras, favorecendo áreas imediatamente próximas e principalmente as cidades médias.

Frente a estas transformações surge no debate a tese sobre a desmetropolização no Brasil. Martine (1992) numa primeira análise dos dados censitários de 1991 chegou a utilizarse dessa nomenclatura. Contudo, em texto posterior de 1994, o autor retifica-se entendendo tratar-se muito mais de uma diminuição no ritmo de crescimento demográfico das grandes metrópoles.

A propósito, Azzoni (1995) tratando do que denomina 'formação socioespacial metropolitana” observa que a "desmetropolização" (raciocínio derivado da queda das taxas de crescimento de metrópoles brasileiras) não encontra apoio nos dados empíricos (exceto no Rio de Janeiro, São Paulo e Belém). Nos demais casos, apesar da queda nas taxas de crescimento o peso das áreas metropolitanas nos respectivos estados continua aumentando.

\section{5- MIGRAÇÃO COMO FATORES DE EXPULSÃO E ATRAÇÃO E FORÇAS CENTRÍPETA E CENTRÍFUGA ${ }^{14}$}

As tendências gerais dos deslocamentos populacionais no Brasil até a década de 70 estavam ancoradas, basicamente, nos seguintes eixos: a) na enorme transferência de população do meio rural para o urbano que, refletindo as distintas etapas do processo de desenvolvimento, contribuiu para o esvaziamento do campo; b) nas migrações com destino às

\footnotetext{
${ }^{14}$ Em Pacheco e Patarra (1998) encontra-se uma resenha sobre as migrações internas e industrialização no Brasil. Cadernos do Leste

Artigos Científicos

Belo Horizonte, Edição Especial, 2000 a 2008
} 
fronteiras agrícolas; c) no intenso fenômeno da metropolização e na acentuada concentração urbana.

$\mathrm{Na}$ vertente da migração rural-urbana, Singer (1972) contextualizou esses movimentos migratórios no bojo do processo de industrialização em curso, onde os deslocamentos populacionais - com origem rural e destino urbano consubstanciaram a força de trabalho necessária à etapa de acumulação capitalista. As áreas rurais estagnadas ou em processo de transformação, componentes dos chamados "fatores de estagnação" e "fatores de mudanças”, explicavam os de fluxos migratórios procedentes de lugares, onde as 'causas' e 'motivos' da migração eram resultantes da desestabilização de relações de produção pretéritas e de transformações econômicas globais da sociedade. Os excedentes populacionais do meio rural constituíam formidáveis transferências populacionais para as cidades e incorporação parcial desses contingentes no mercado de trabalho industrial em expansão.

Embora, os movimentos migratórios de tipo rural-urbano fossem a principal força redistributiva da população, principalmente nos anos 50 e 60, o panorama dos movimentos migratórios no Brasil foi ganhando complexidade a partir de então, até mesmo pelo novo padrão de desenvolvimento econômico que o País viria assistir ${ }^{15}$.

Segundo Martine e Camargo (1984), o cenário da distribuição espacial da população brasileira a partir dos anos 60 foi movido por forças centrífugas, com a expansão populacional (migrações inter-regionais) rumo às áreas de fronteiras, e por forças centrípetas, com a migração rural-urbana em direção às grandes cidades do Sudeste, particularmente para a Região Metropolitana de São Paulo.

Já nos anos 70, no interior desta bipolaridade, a emigração das áreas de fronteiras agrícolas em direção às cidades maiores colaborava com as forças de concentração (forças centrípetas), quando a urbanização nacional operava-se em um padrão ainda concentrador, que levava ao estabelecimento de um processo de distribuição da população que tendia a privilegiar os grandes centros urbanos do Sudeste (Martine, 1987).

\footnotetext{
${ }^{15}$ Veja-se, dentre outros, Cano (1977), Pacheco e Patarra (1998), Martine (1987). Cadernos do Leste Artigos Científicos 
Com os anos 80 essas forças se redefinem. As forças centrífugas, resultantes da atração exercida pelas fronteiras agrícolas, perderam sua importância (ainda nos anos 70$)^{16}$, muito embora seus desdobramentos tenham ainda se refletido, nos anos 80 e início dos 90, em termos de movimentos migratórios. Já as forças centrípetas, em especial a exercida pela metrópole de São Paulo, arrefecem-se, porém sem desaparecerem. ${ }^{17}$ Compondo um movimento mais amplo de redistribuição populacional, a Região Metropolitana de São Paulo, ao mesmo tempo em que ainda se mantém como o maior centro de recepção migratória, passava também a destacar-se pela importância de seu volume emigratório em nível nacional, emprestando recentes características ao processo de distribuição espacial da população e redefinindo alguns aspectos da migração interna.

Nesse sentido, no contexto deste debate, estudos recentes ${ }^{18}$ sobre possíveis impactos do processo de desconcentração das atividades industriais na redistribuição espacial da população sugerem: a) transformações mais expressivas no âmbito do Estado de São Paulo, indicando um incipiente processo de desconcentração populacional; b)aumento da urbanização nas regiões e estados que se constituíram em canais da desconcentração industrial (Minas Gerais, Rio Grande do Sul, Paraná, Centro-Oeste); c) expressivos fluxos migratórios de retorno para estados tradicionalmente emissores de população; d) incremento das migrações intraregionais; e) relativa desconcentração do sistema urbano brasileiro, com a inserção das cidades pequenas e intermediárias nas dinâmicas das aglomerações urbanas, em especial as metropolitanas.

\section{6- DESCONCENTRAÇÃO DEMOGRÁFICA E DESCONCENTRAÇÃO ECONÔMICA}

Não há dúvidas sobre o fato de a desconcentração demográfica coincidir com a desconcentração econômica em vários aspectos. É verdade que as deseconomias de aglomeração tanto atingem as atividades econômicas quanto a população, assim como

\footnotetext{
${ }^{16}$ Em Martine (1987) encontra-se a evolução e declínio das áreas de fronteira no Brasil.

${ }^{17}$ Veja-se Baeninger (1999).

${ }^{18}$ Veja-se Negri (1996), Baeninger (1999), Patarra et al (1997), Cunha (1998 e 1999), Pacheco (1998), Martine (1994), IPEA/IBGE/NESUR (2000), dentre outros.

Cadernos do Leste

Artigos Cientificos

Belo Horizonte, Edição Especial, 2000 a 2008
} 
esforços governamentais voltados à interiorização do desenvolvimento podem dispersar atividades e população. No entanto, a década de 70 , caracterizada pelo início de um processo de desconcentração industrial, não experimentou uma desconcentração populacional da mesma magnitude. Haveria uma possível defasagem entre estas duas dinâmicas? De qualquer modo no âmbito destas "desconcentrações" foi eloquente a participação das periferias metropolitanas como redutos de atração de imigrantes regionais e como áreas de grande expansão da urbanização brasileira.

Por outro lado, não obstante os investimentos direcionados às cidades médias no período, os resultados efetivos só se tornam mais notáveis na década de 80 . De fato, somente nessa década, as evidências de desconcentração populacional ganham mais nitidez, quando ocorre uma forte redução das taxas de crescimento metropolitano, em especial nas metrópoles industrializadas; áreas de onde partiram expressivos contingentes de migrantes de retorno e um intenso fluxo de saída de pessoas rumo ao interior dos estados.

O deslanchar do processo de desconcentração urbana no Brasil articula-se, na verdade, com a predominância dos movimentos migratórios de tipo urbano-urbano, a partir dos anos 70. Esse fenômeno vem contribuindo diretamente para a difusão do processo de urbanização para o resto do País, por meio de uma rede urbana mais dispersa e interiorizada, por onde se inicia uma expansão sem precedentes de muitos núcleos urbanos de porte médio dotados de importantes áreas de influência.

A par dessas evidências aumentam os movimentos intra-regionais que, direta ou indiretamente, participam do processo de desconcentração populacional. Assim, deve-se considerar com especial atenção os efeitos da dinâmica econômica sobre novas trajetórias dos movimentos populacionais. Aqui a discussão baseada na dinâmica industrial é insuficiente para explicar a redistribuição intra-regional das populações, sobretudo no Norte, CentroOeste e mesmo no Nordeste, áreas caracterizadas por distintas atividades econômicas, tais como turismo, serviços, agricultura, agroindústria etc.

Do ponto de vista da dinâmica econômica, as duas décadas subsequentes à de 70 já não registraram o mesmo ímpeto da industrialização desconcentrada como o fora naquele período; mesmo assim, "o primeiro quinquênio dos anos 80 marca um grande avanço do processo de Cadernos do Leste 
interiorização da indústria no Estado de São Paulo" (Negri, 1996:216). A partir de 1985 e início dos 90, esse processo de desconcentração industrial perdeu dinamismo, em função do esgotamento dos ciclos de investimentos dos anos setenta. Na certa, a interiorização industrial prosseguiu, mas em um ritmo menos intenso, dada a perda de dinamismo da indústria em seu conjunto (Pacheco, 1998).

Assim, a década de 1980 traz novas questões que se incorporam ao debate. Nesse momento, a indústria brasileira passou a ter um desempenho bem inferior ao da década anterior, resultado das políticas de ajuste macroeconômico do início da década, da trajetória da inflação crônica do seu final e dos fracassos nas políticas econômicas do período. Isto acarretou um decréscimo absoluto do produto industrial introduzindo mudanças na estrutura industrial. Registrou-se, de um lado, a redução de participação dos setores mais afetados pela crise (bens intermediários e de bens de capital), mas, de outro lado, houve um aumento dos setores que conseguiam conquistar mercados internacionais, a exemplo da agroindústria, siderurgia, calçados etc. (Negri, 1996).

Esgotava-se, portanto, o modelo desenvolvimentista baseado no estado interventor. Paralelamente escasseavam-se os recursos financeiros que alavancavam os projetos e investimentos de décadas anteriores; porquanto alteravam-se os fluxos financeiros internacionais, reorientados a favor de economias desenvolvidas. As dificuldades de financiamento do Estado e a crise da dívida externa deram mais visibilidade a crise fiscal do período, fazendo desacelerar fortemente o nível de atividade econômica e, por conseguinte, expandir a chamada dívida social do País.

Estavam, assim, lançados os fundamentos que explicariam o aumento da pobreza urbana nas áreas metropolitanas, onde, distintamente da década de 1970, escasseavam-se os recursos públicos aplicáveis em transporte, habitação e saneamento; setores que, além de tudo, empregavam grande volume de mão-de-obra, amenizando as desigualdades sociais.

\section{7- REESTRUTURAÇÕES E CRISE NOS ANOS 90}

Cadernos do Leste

Artigos Cientificos

Belo Horizonte, Edição Especial, 2000 a 2008 
Nos 90 houve o decréscimo anual de cerca de 15,9 mil postos de trabalho, o que resultou na queda no emprego industrial. Segundo Porchmann (2001:102):

(...) Enquanto na década de 80 a evolução média anual do emprego formal foi positiva, de 2,2\%, nos anos 90 foi negativa, de $-17,8 \%$. No setor de comércio e serviços, o desempenho mostrou-se positivo, mas na indústria da construção civil e na indústria de transformação declinou.

Coutinho assinala que o longo período de crise econômica da década de 90, agravado pela própria herança de iniquidades que o País carrega, forçaram as empresas a introduzir os chamados "ajustamentos defensivos". A modernização e enxugamento administrativo das empresas; a compressão na produção industrial; a intensa terceirização e subcontratação a partir dos anos 90; e, a combinação de recessão com abertura econômica resultaram na eliminação de cerca de 1,5 milhão de empregos formais entre 1983 e 1993 na indústria de transformação. Ainda que boa parte desse quantum tenha se transferido para as atividades terceirizadas, várias ocupações profissionais desapareceram do mercado de trabalho. No cômputo final, a "tendência estrutural que apresenta indícios claros de permanência é da reestruturação do processo de trabalho, em virtude da introdução de inovações tecnológicas (...) e queda do emprego urbano formal" (Coutinho, 1995:59-60)).

Nesse quadro, cabe retomar o debate tendo como pergunta central se a reestruturação produtiva, privilegiando espaços urbanos dinâmicos, implicará na reconcentração da indústria. Segundo Negri e Pacheco (1993), as novas dimensões espaciais da indústria, que sinalizam características do atual processo de reestruturação econômica em nível internacional ${ }^{19}$, continuarão a encontrar em São Paulo espaços apropriados para o desenvolvimento dessa etapa do capitalismo. Cano (1995) e Diniz (1995) também apontam para uma possível reconcentração da indústria, principalmente aquela de alta tecnologia, em regiões paulistas, como Campinas.

Frente à discussão econômica mais recente, pode-se pensar em uma articulação entre as dinâmicas da desconcentração/reconcentração econômica e desconcentração/reconcentração

19 Essa tendência é marcada pela dispersão geográfica da produção industrial; veja-se Piore e Sabel (1984); Harvey (1992); Sassen (1988); Benko(1996), dentre outros.

Cadernos do Leste

Artigos Cientificos

Belo Horizonte, Edição Especial, 2000 a 2008 
populacional? Diante de uma suposta reconcentração econômica desde meados dos anos 90, haveria uma remetropolização da população?

Essas são questões que devem permear o debate sobre dinâmica econômica e distribuição da população ao longo desta década. De qualquer modo, pode-se supor que dificilmente haveria uma reconcentração da população, nos moldes da concentração urbana ocorrida entre os anos 1930 e 1970. Em primeiro lugar, como ilustrou a década de 70, a população não obedece linearmente à lógica de instalação das atividades econômicas. Em segundo lugar, o novo paradigma da indústria ancora-se na menor absorção de mão-de-obra, privilegiando o trabalhador mais qualificado. Por último, os patamares de urbanização alcançados fora do eixo Centro-Sul absorvem contingentes populacionais que potencialmente poderiam migrar para as chamadas áreas históricas de concentração econômica, consolidando uma rede urbana relativamente desconcentrada.

\section{8- MIGRAÇÕES INTERNAS RECENTES}

Como se viu, as migrações internas assumem maior complexidade a partir dos anos 80 em função, particularmente, do predomínio das migrações entre áreas urbanas. O entendimento do processo de reorganização da população no espaço desloca-se, portanto, do eixo de análise via migração rural-urbana, força motriz das análises centrípetas.

As migrações internas das últimas décadas experimentam alterações em sua dinâmica resultantes, inclusive, da menor pressão dos grandes movimentos rurais (o êxodo rural dos anos 80 foi da ordem de 10,6 milhões de pessoas) sobre os centros urbanos de maior porte. O próprio patamar em que se encontra o processo de urbanização vem contribuindo para a predominância do movimento de tipo urbano-urbano, onde emergem e mesclam-se variadas modalidades de deslocamentos populacionais. Os anos 80 introduziram significativas mudanças nos volumes e características dos movimentos migratórios. Algumas dessas mudanças referem-se à diversificação dos fluxos intra-regionais nas Grandes Regiões; ao decréscimo dos movimentos interestaduais de longa distância; ao incremento das migrações Cadernos do Leste Artigos Científicos 
de retorno; à inflexão no ritmo de crescimento metropolitano; ao surgimento de outras áreas de imigração; ao aumento das migrações de curta distância, em especial a intrametropolitana e intra-regional. ${ }^{20}$

Tudo isso confere novos significados aos conceitos de migrante, de áreas de origem e áreas de destino, áreas de atração e áreas de expulsão. Ao lado dos tradicionais fluxos migratórios passam também a sobressair outros movimentos. A recorrência e incremento das modalidades de deslocamentos de tipo pendular, circular, envolvendo dupla residência, no atual processo de urbanização complexificam o entendimento da relação migração/emprego.

Os movimentos migratórios do final dos anos 80 até o início dos 90 parecem apontar para mudanças significativas no processo de distribuição espacial da população brasileira. ${ }^{21}$ As tendências recentes da migração interna no Brasil suscitam análises interpretativas que enriquecem o debate, mas o tornam mais intrincado. As transformações ocorridas no fenômeno migratório poderiam estar: i) configurando um novo padrão migratório brasileiro (Brito, 1997); ii) materializando transformações ocorridas na sociedade e em sua dinâmica econômica no mesmo período (Pacheco e Patarra, 1998); iii) apontando variações de um mesmo processo historicamente referenciado no tempo e no espaço (Cunha, 1999); iv) traduzindo a própria expansão dos espaços das migrações internas (Baeninger, 1999).

Comparando-se as transformações recentes no processo de distribuição espacial da população e a classificação elaborada por Martine e Camargo (1984) referente à distribuição nos anos 70, pôde-se constatar importantes alterações:

i) As áreas classificadas pelos autores como "áreas de fronteira em expansão" (Região Norte e Mato Grosso) foram as que ganharam maior impulso, tornandose áreas consolidadas no período 1986-1991, e já demonstrando sinais efetivos de perda de dinamismo no período 1991-1996;

\footnotetext{
${ }^{20}$ Esta síntese baseia-se em trabalhos sobre o tema presentes nos Anais dos Encontros da ABEP ao longo dos anos 90, bem como nos dos Encontros Nacionais de Migração de 1997 e 1999 e nas Revistas da ABEP. ${ }^{21}$ Veja-se: Martine (1984, 1987, 1994), Martine e Carvalho (1989), Brito (1997), Cunha (1999), Pacheco e Patarra (1998) e Baeninger (1999).
}

Cadernos do Leste 
ii) As "áreas de fronteira consolidada" (de forte evasão populacional nos $70 \mathrm{em}$ função do esgotamento das fronteiras agrícolas), ainda no período 1981-1991, foram importantes redutos de emigração (especialmente do Paraná para São Paulo e Mato Grosso e do Maranhão em direção ao Pará), porém já arrefecidos entre 1991-1996. Note-se que Goiás e Mato Grosso do Sul, nos anos 80, registravam ganhos populacionais;

iii) Alguns espaços das "áreas tradicionais de emigração" (Nordeste, Minas Gerais, Espírito Santo, Santa Catarina e Rio Grande do Sul), nos anos 80 e 90, experimentam uma reversão de tendências na dinâmica migratória. Os estados do Espírito Santo, de Santa Catarina, Minas Gerais chegaram a apresentar ganhos populacionais, enquanto o Nordeste diminui expressivamente o seu nível de perdas.

iv) Áreas do "núcleo industrial" constituída pelos Estados de São Paulo e Rio de Janeiro. O Rio de Janeiro já havia demonstrado, nos anos 70, uma desaceleração em sua força de atração migratória, embora ainda se configure como área de absorção migratória nos fluxos migratórios com estados de outras Regiões; no contexto do Sudeste, no entanto, vêm manifestando perdas populacionais. Quanto ao Estado de São Paulo, apesar da redução em seus volumes de imigrantes, este ainda continuou sendo o principal pólo de atração populacional no Brasil.

Os dados dos últimos 30 anos, como sugerem as evidências apresentadas a seguir, parecem indicar o aprofundamento de tendências observadas recentemente, quais sejam: manutenção do menor ritmo de crescimento das principais metrópoles industriais, taxas de crescimento urbano elevadas para as antigas regiões de fronteiras agrícolas (Norte e Centro Oeste), crescimento significativo de cidades médias e pequenas, e predominância dos deslocamentos populacionais intra-regionais.

\section{9- EVIDÊNCIAS DA URBANIZAÇÃO DESCONCENTRADA}

Cadernos do Leste

Artigos Cientificos

Belo Horizonte, Edição Especial, 2000 a 2008 
É indiscutível que boa parte da urbanização nas últimas décadas associa-se aos efeitos multiplicadores derivados do "espraiamento" originários da histórica concentração urbanoindustrial no Sudeste. De fato, nessa região, localizavam-se quase metade dos centros urbanos do Brasil em 2000, dentre os quais as três principais áreas metropolitanas.

Esse espraiamento industrial estimulou o adensamento do sistema urbano brasileiro e os vínculos de interdependência e complementaridade entre cidades estratégicas postadas nas diferentes partes do sistema. Tais pontos conferem lógica e sentido à rede, e tendem a sintetizar espacialmente o processo de mudanças estruturais de longa duração. Esses espaços vêm emoldurando localizações alternativas para investimentos econômicos e permitindo o surgimento de novos papéis e distintos níveis de especialização econômica passíveis de cristalizar desenhos pelos quais circulam mercadorias, pessoas e capitais, não necessariamente circunscritos a um perímetro definido no Sul-Sudeste, como propõe Diniz (1993) ${ }^{22}$.

Aliás, é mais provável que o sistema urbano brasileiro consolide seu desenho para formas híbridas diversas, dentre as quais poderá ganhar nitidez um conjunto de estruturas espaciais articuladas de desenvolvimento denso, onde novas oportunidades de investimentos públicos e privados poderão contribuir para reforçar tendências atuais e reforçar a interiorização da rede de cidades.

Nesse sentido, Motta e Ajara (1999:14) afirmam que:

os diversos tipos de articulação e integração espacial existente entre os centros urbanos, ao mesmo tempo que expressam sua inserção e o papel desempenhado na estrutura produtiva, refletem os diversos arranjos possíveis e engendram uma configuração espacial peculiar para cada segmento da rede urbana.

A urbanização brasileira marcou, sem dúvida, o processo de redistribuição populacional no País. Basta dizer que a expansão urbano-industrial tornou os centros urbanos responsáveis por 90\% de tudo o que aqui é produzido; o que, evidentemente, acarretou um vertiginoso processo de concentração de pessoas e atividades em algumas das maiores

\footnotetext{
${ }^{22}$ O autor, em Diniz e Crocco (1996), quando procura avaliar a reestruturação econômica e o novo mapa da indústria brasileira, concorda, de forma ainda relutante, que teria iniciado no País uma relativa dispersão geográfica em direção à maioria das regiões e estados, não obstante a possibilidade de uma reconcentração geográfica no centro-sul, em uma região que iria do Rio Grande do Sul até o centro de Minas Gerais.
}

Cadernos do Leste

Artigos Cientificos

Belo Horizonte, Edição Especial, 2000 a 2008 
metrópoles do planeta: São Paulo e Rio de Janeiro, respectivamente $3^{\mathrm{a}}$ e $15^{\mathrm{a}}$ maiores cidades do mundo.

De acordo com os resultados preliminares do Censo Demográfico de 2000, 81,2\% da população brasileira residiam em áreas urbanas, devendo chegar a 88\% em 2025, segundo projeções nas Nações Unidas (IPEA, 2000).

Não obstante o estoque de população residente nas grandes concentrações metropolitanas, cabe reafirmar que o Brasil, ao longo dos anos 90, continuou 
experimentando um importante processo de redistribuição de sua população no espaço, cuja marca distintiva continua sendo a interiorização do crescimento e a formação de novas aglomerações urbanas (IPEA/ IBGE / NESUR-UNICAMP, 2000).

De fato, nesse estudo do IPEA/IBGE/NESUR-UNICAMP pode-se notar que o chamado "espraiamento" da urbanização brasileira se traduz na própria interiorização do fenômeno da metropolização, como atestam os exemplos de Goiânia e Campinas (SP), ou das aglomerações urbanas não-metropolitanas, como Cabo Frio (RJ), Ipatinga (MG), Itajaí (SC), entre outras. Ao lado disso, o estudo registra o grande crescimento de centros urbanos médios - aqueles com população variando entre 100 mil e 500 mil habitantes. Uma tentativa de explicação para tais mudanças reside na terceirização das economias urbanas metropolitanas, que têm provocado a redução do emprego assalariado e queda nos níveis de renda, o que refletiria na diminuição da capacidade de absorção de migrantes.

Do ponto de vista mais restrito aos estudos populacionais cabe retomar a discussão mais geral sobre as novas tendências de desconcentração populacional examinando: a inflexão do crescimento metropolitano; a dinâmica do crescimento populacional urbano e a rede de cidades; e, a dinâmica das áreas urbanas não-primazes.

\section{0- DESACELERAÇÃO NO RITMO DE CRESCIMENTO METROPOLITANO}

Apesar de as regiões metropolitanas terem se configurado como receptoras de grandes contingentes populacionais há várias décadas, no período 1970-1980 já se podia evidenciar um arrefecimento no ritmo de crescimento da população residente nessas áreas: a taxa média de crescimento populacional metropolitano passou de 4,7\% a.a., entre 1960-1970, para 3,8\%, entre 1970-1980, situando-se já nessa década a níveis mais baixos que a taxa média de crescimento da população urbana brasileira que havia sido de 4,44\% a.a. Mesmo assim, os fluxos migratórios que haviam se dirigido para essas metrópoles justificavam apontar a 
prevalência do padrão de concentração populacional: 5.705.021 pessoas $^{23}$ se destinaram às regiões metropolitanas no período 1970-1980, correspondendo a 22,5\% da migração intermunicipal nacional.

Nos anos 80 e 90, no entanto, as taxas de crescimento da população metropolitana nacional apresentaram decréscimos consideráveis, 1,99\% a.a. entre 1980/91 e 1,79\% a.a. entre 1991-2000. A desaceleração no ritmo de crescimento metropolitano teve nos anos 80 seu ponto de inflexão, consolidando, inclusive, a tendência incipiente dos anos 70 de maiores taxas de crescimento para o conjunto da população urbana brasileira (2,97\% a.a., entre 19801991, e 2,42\% a.a., de 1991-2000) do que para a população metropolitana (Tabela 1).

Tabela 1

População Total e Taxas de Crescimento (\% a.a.)
Regiões Metropolitanas
$1970-2000$

\begin{tabular}{|c|c|c|c|c|c|c|c|}
\hline Regiões & & População & otal & & Taxas de C & Cresciment & to (\% aa) \\
\hline Metropolitanas & 1970 & 1980 & 1991 & 2000 & $1970-1980$ & 1980-1991 & 1991-2000 \\
\hline TOTAL & 23.730 .895 & 32.126 .519 & 39.759 .370 & 46.657 .093 & 3,79 & 1,99 & $\overline{1,79}$ \\
\hline São Paulo & 8.139 .730 & 12.588 .725 & 15.444 .941 & 17.833 .511 & 4,46 & 1,88 & 1,61 \\
\hline Rio de Janeiro & 6.891 .521 & 8.772 .265 & 9.814 .574 & 10.871 .960 & 2,45 & 1,26 & 1,14 \\
\hline Recife & 1.791.322 & 2.347 .146 & 2.858.147 & 3.249 .754 & 2,74 & 1,22 & 1,44 \\
\hline Belo Horizonte & 1.658 .482 & 2.609 .583 & 3.436 .060 & 4.251 .350 & 4,70 & 2,42 & 2,39 \\
\hline Porto Alegre & 1.574 .239 & 2.285 .140 & 3.038 .792 & 3.507 .624 & 3,84 & 2,16 & 1,61 \\
\hline Salvador & 1.147 .821 & 1.766 .614 & 2.496 .521 & 3.018 .326 & 4,43 & 3,04 & 2,13 \\
\hline Fortaleza & 1.036 .779 & 1.580 .074 & 2.307 .017 & 2.920 .923 & 4,29 & 2,67 & 2,66 \\
\hline Curitiba & 821.233 & 1.440 .626 & 2.000 .805 & 2.716 .288 & 5,80 & 3,03 & 3,46 \\
\hline Belém & 669.768 & 1.021 .486 & 1.401 .305 & 1.794 .981 & 4,30 & 3,43 & 2,79 \\
\hline BRASIL URBANO & 52.084 .984 & 80.436 .409 & 110.990 .990 & 137.697 .439 & 4,44 & 2,97 & 2,42 \\
\hline
\end{tabular}

Os anos 70, de fato, caracterizaram-se pelo acentuado fenômeno da metropolização, principalmente para as regiões de Belém, Fortaleza, Salvador, Belo Horizonte, São Paulo e Curitiba, que registraram taxas de crescimento superiores ou próximas à média do crescimento da população urbana no período. O incremento absoluto da população nessas

\footnotetext{
${ }^{23}$ Refere-se às pessoas que mudaram de município, pelo menos uma vez, na década; não inclui a migração intrametropolitana.

Cadernos do Leste

Artigos Cientificos

Belo Horizonte, Edição Especial, 2000 a 2008
} 
regiões, no período 1970-1980, foi de 8,3 milhões de pessoas, correspondendo a 30\% do incremento da população urbana nacional.

No período 1980-1991 pode-se observar a desaceleração no ritmo de crescimento populacional metropolitano, com apenas Salvador, Curitiba e Belém crescendo a taxas superiores à média da população urbana nacional no período, ao passo que as maiores áreas metropolitanas - São Paulo e Rio de Janeiro - passavam a apresentar taxas de crescimento até mesmo inferiores à média metropolitana: 1,88\% a.a. e 1,26\% a.a., respectivamente, contra $1,99 \%$ a.a.

Os resultados do Censo Demográfico de 2000 indicam que os anos 90 fazem avançar o processo de desaceleração do crescimento metropolitano, sobretudo em São Paulo (que registrou entre 1991-2000 uma taxa de crescimento de 1,61\% a.a.), Rio de Janeiro (1,14\% a.a.) e Porto Alegre (1,61\% a.a.), com ritmos bem inferiores à média urbana nacional (2,42\% a.a.) e metropolitana (1,79\%a.a.). As regiões metropolitanas de Recife, Belo Horizonte e Fortaleza mantiveram suas taxas de crescimento nesse período bastante próximas às verificadas para a década anterior. À exceção de Curitiba, que registrou uma elevação na sua taxa de crescimento metropolitano (3,03\% a.a., nos 80, para 3,46\% a.a., nos 90), pode-se verificar nas demais regiões a continuidade do arrefecimento do crescimento metropolitano.

O Brasil metropolitano dos anos 90, portanto, cresce menos que em décadas anteriores e menos ainda que as demais áreas urbanas do País. Não obstante o fato de que entre 1970 e 2000 a população residente nas nove antigas áreas metropolitanas tenha passado de 23.717.028 habitantes para 50.164.717, a importância do processo de desaceleração metropolitana é revelada pela expressiva perda de participação relativa das populações metropolitanas no total da população urbana do País.

De fato, em 1970, a população metropolitana nacional respondia por 45,56\% da população urbana brasileira, passando para 33,88\%, em 2000 (Tabela 2). Os maiores decréscimos foram registrados nas metrópoles de São Paulo - que representava 15,6\% da população urbana nacional em 1970 e 1980, passando para 12,9\%, em 2000-, e Rio de Janeiro, de 13,2\% diminuiu para 7,9\%, respectivamente. Fortaleza, Curitiba e Belém elevaram

Cadernos do Leste

Artigos Cientificos

Belo Horizonte, Edição Especial, 2000 a 2008 
ligeiramente suas participações relativas no total do urbano brasileiro, apesar de representar pouco no conjunto da população urbana (em torno de $2 \%$ ).

Essas evidências já permitem indicar que até o ano 2000, mesmo que possa ter havido algumas oscilações regionais, não se observou a retração no processo de desaceleração metropolitana no Brasil, a qual pudesse vir a se converter em uma possível reconcentração metropolitana.

Tabela 2

Participação Relativa (\%) no Total da População Urbana Nacional Regiões Metropolitanas Antigas

1970-2000

\begin{tabular}{l|r|r|r|r}
\hline Regiões Metropolitanas & 1970 & 1980 & 1991 & 2000 \\
\hline TOTAL & 45,56 & 39,94 & 35,82 & 33,88 \\
São Paulo & 15,63 & 15,65 & 13,92 & 12,95 \\
Rio de Janeiro & 13,23 & 10,91 & 8,84 & 7,90 \\
Recife & 3,44 & 2,92 & 2,58 & 2,36 \\
Belo Horizonte & 3,18 & 3,24 & 3,10 & 3,09 \\
Porto Alegre & 3,02 & 2,84 & 2,74 & 2,55 \\
Salvador & 2,20 & 2,20 & 2,25 & 2,19 \\
Fortaleza & 1,99 & 1,96 & 2,08 & 2,12 \\
Curitiba & 1,58 & 1,79 & 1,80 & 1,97 \\
Belém & 1,29 & 1,27 & 1,26 & 1,30 \\
& & & & \\
BRASIL URBANO & 100,00 & 100,00 & 100,00 & 100,00 \\
\hline Fonte: FIBGE, Censos Demográficos de $1980,1991 \mathrm{e} \mathrm{2000.}$
\end{tabular}

Considerando a distribuição da população da área metropolitana no total urbano dos respectivos estados (Tabela 3) nota-se que de 1970 para o ano 2000 houve, de modo geral, um incipiente processo de desconcentração populacional metropolitano. As regiões metropolitanas que mais perderam peso relativo no total urbano de seus estados foram Belém (respondia por 65,5\% e passou para 43,6\%), Recife (de 63,7\% para 53,7\%) e Rio de Janeiro (de $87,2 \%$ para $78,8 \%$ ). Com pequenas oscilações, as demais regiões vêm mantendo mais ou menos estável, ao longo de quatro décadas, as mesmas participações no total da população urbana de seus estados. 
Tabela 3

Participação Relativa no Total Urbano dos Respectivos Estados

Regiões Metropolitanas

\begin{tabular}{|c|c|c|c|c|}
\hline \multirow{2}{*}{$\begin{array}{l}\text { Regiões } \\
\text { Metropolitanas }\end{array}$} & \multicolumn{4}{|c|}{ Participação Relativa (\%) } \\
\hline & 1970 & 1980 & 1991 & 2000 \\
\hline TOTAL & 55,19 & 50,05 & 46,60 & 45,18 \\
\hline Belém & 65,54 & 61,26 & 53,97 & 43,61 \\
\hline Fortaleza & 58,24 & 56,22 & 55,43 & 55,07 \\
\hline Recife & 63,73 & 62,02 & 56,58 & 53,70 \\
\hline Salvador & 37,20 & 37,91 & 35,58 & 34,45 \\
\hline Belo Horizonte & 27,37 & 29,05 & 29,15 & 29,07 \\
\hline Rio de Janeiro & 87,17 & 84,61 & 80,45 & 78,79 \\
\hline São Paulo & 57,02 & 56,72 & 52,69 & 51,65 \\
\hline Curitiba & 32,79 & 32,21 & 32,28 & 34,90 \\
\hline Porto Alegre & 44,31 & 43,52 & 43,43 & 42,20 \\
\hline
\end{tabular}

Fonte: FIBGE, Censos Demográficos de 1980, 1991 e 2000.

1970-2000

Assim, no contexto estadual, dado o enorme volume de população residente nos espaços metropolitanos, a desconcentração que se processa reflete muito pouco em termos de indicadores. No caso de São Paulo, por exemplo, a Região Metropolitana de São Paulo respondia, em 1970, por 57\% da população urbana paulista, passando para 51\%, em 2000, embora se saiba das expressivas perdas populacionais dessa área em direção ao Interior do Estado.

No entendimento do processo de dispersão da urbanização pelo País é preciso que se considere - além das trajetórias populacionais das antigas regiões metropolitanas - os processos recentes que envolvem a criação de novas áreas metropolitanas (Brasília, Vitória, Campinas, Santos, Natal e Goiânia). Essas novas metrópoles chegaram a exibir uma taxa de crescimento de 5,83\% a.a. nos anos 70, passando para 3,54\% a.a., entre 1980-1991, e 2,8\% a.a. no período 1991-2000; valores bastante superiores às médias de crescimento da população urbana do País e das antigas metrópoles. Enquanto as RM's Antigas vêm perdendo peso relativo no total da população urbana do Brasil, as Novas RM's registram elevação, representando, 7,78\% do total urbano nacional no ano 2000. (Tabela 4).

Cadernos do Leste

Artigos Científicos

Belo Horizonte, Edição Especial, 2000 a 2008 


\section{Tabela 4}

\section{Populações Metropolitanas, Taxas de Crescimento (\% a.a.) e Participação Relativa $(\%)$ \\ Regiões Metropolitanas Antigas* e Novas**}

\begin{tabular}{|c|c|c|c|c|c|c|c|}
\hline \multirow{2}{*}{$\begin{array}{l}\text { Regiões } \\
\text { Metropolitanas }\end{array}$} & \multicolumn{4}{|c|}{ População Total } & \multicolumn{3}{|c|}{ Taxas de Crescimento (\%aa) } \\
\hline & 1970 & 1980 & 1991 & 2000 & $1970-1980$ & $0-1991$ & $1991-2000$ \\
\hline RMs Antigas & 23.730 .895 & 32.126 .519 & 39.759.370 & 46.657 .093 & 3,08 & 1,96 & 1,79 \\
\hline RMs Novas & 3.236 .578 & 5.703 .896 & 8.360.908 & 10.720 .429 & 5,83 & 3,54 & 2,80 \\
\hline Total RMs & 26.967 .473 & 37.830 .415 & 48.120 .278 & 57.377 .522 & 3,44 & 2,21 & 1,97 \\
\hline \multicolumn{8}{|c|}{ Participação Relativa na População Urbana do Brasil } \\
\hline RMs Antigas & 45,56 & 39,94 & 35,82 & 33,88 & & & \\
\hline RMs Novas & 6,21 & 7,09 & 7,41 & 7,78 & & & \\
\hline TOTAL RMs & 51,77 & 47,03 & 43,23 & 41,66 & & & \\
\hline
\end{tabular}

Fonte: FIBGE, Censos Demográficos de 1980, 1991 e 2000.

1970-2000

(*) Incluem as noves regiões metropolitanas criadas nos anos 70: Belém, Belo Horizonte, Curitiba, Fortaleza, Porto Alegre, Recife, Rio de Janeiro, Salvador e São Paulo.

(**) Incluem as regiões metropolitanas de Campinas, Natal, Vitória, Brasília, Santos e Goiânia.

Embora as RM's Novas concentrem um volume de população (cerca de 10,7 milhões, em 2000) inferior ao das RM’s Antigas (em torno de 46 milhões de habitantes), essas áreas vêm contribuindo, ao nível nacional e estadual, para a desaceleração do crescimento das principais metrópoles nacionais. A Região Metropolitana de Brasília, por exemplo, têm absorvido uma expressiva migração nordestina, que em outras décadas - muito provavelmente - teria se dirigido a São Paulo ou Rio de Janeiro. As regiões metropolitanas de Campinas e Santos, no contexto estadual, também se configuram como áreas de desconcentração população da RMSP em direção ao Interior.

Desse modo, a compreensão dos processos de desconcentração urbana e desaceleração metropolitana remete à própria conformação e distribuição da população no sistema de cidades brasileiras. 


\section{1- DISTRIBUIÇÃO DA POPULAÇÃO NA REDE URBANA BRASILEIRA: O PAPEL DAS AGLOMERAÇÕ̃ES NÃO-METROPOLITANAS E DAS CIDADES NÃO-PRIMAZES}

Considerando a distribuição populacional na morfologia do sistema urbano do país segundo as Grandes Regiões é possível observar a crescente importância de aglomerações não-metropolitanas e de localidades menores na reorganização da população no espaço (Tabela 5).

Tabela 5

População segundo Morfologia da Rede Urbana Brasileira* Grandes Regiões - 1980-2000

\begin{tabular}{|c|c|c|c|c|c|c|c|c|}
\hline \multirow{2}{*}{$\begin{array}{l}\text { Regiões e Centros } \\
\text { Urbanos }\end{array}$} & \multicolumn{3}{|c|}{ População Total } & \multicolumn{3}{|c|}{ Distribuição } & \multirow{2}{*}{\multicolumn{2}{|c|}{$\begin{array}{l}\text { Taxas de Crescimento } \\
1980-1991 \text { 1991-2000 }\end{array}$}} \\
\hline & 1980 & 1991 & 2000 & 1980 & 1991 & 2000 & & \\
\hline Norte & 6623397 & 10030556 & 12919949 & 100,00 & 100,00 & 100,00 & 3,85 & 2,85 \\
\hline RM & 1021486 & 1401305 & 1794981 & 15,42 & 13,97 & 13,89 & 2,92 & 2,79 \\
\hline Municípios de Porte Médio & 1456016 & 2536686 & 3395356 & 21,98 & 25,29 & 26,28 & 5,18 & 3,29 \\
\hline Demais Municípios & 4145895 & 6092565 & 7729612 & 62,59 & 60,74 & 59,83 & 3,56 & 2,68 \\
\hline Nordeste & 34812356 & 42497540 & 47679381 & 100,00 & 100,00 & 100,00 & 1,83 & 1,29 \\
\hline RM's & 6248057 & 8487893 & 10227838 & 17,95 & 19,97 & 21,45 & 2,82 & 2,09 \\
\hline AGUNM & 3149587 & 4736281 & 5829484 & 9,05 & 11,14 & 12,23 & 3,78 & 2,33 \\
\hline Municípios de Porte Médio & 1560673 & 1875118 & 2324260 & 4,48 & 4,41 & 4,87 & 1,68 & 2,41 \\
\hline Demais Municípios & 23854039 & 27398248 & 29297799 & 68,52 & 64,47 & 61,45 & 1,27 & 0,75 \\
\hline Sudeste & 51734125 & 62740401 & 72262411 & 100,00 & 100,00 & 100,00 & 1,77 & 1,58 \\
\hline RM's & 27264082 & 33282548 & 38103026 & 52,70 & 53,05 & 52,73 & 1,83 & 1,51 \\
\hline AGUNM & 4519933 & 6023217 & 7025608 & 8,74 & 9,60 & 9,72 & 2,64 & 1,73 \\
\hline Municípios de Porte Médio & 3424031 & 4403032 & 5132703 & 6,62 & 7,02 & 7,10 & 2,31 & 1,72 \\
\hline Demais Municípios & 16526079 & 19031604 & 22001074 & 31,94 & 30,33 & 30,45 & 1,29 & 1,62 \\
\hline Sul & 19031162 & 22129377 & 25071211 & 100,00 & 100,00 & 100,00 & 1,38 & 1,40 \\
\hline RM's & 4690126 & 6430352 & 8488232 & 24,64 & 29,06 & 33,86 & 2,91 & 3,13 \\
\hline AGUNM & 2107761 & 2809354 & 3405332 & 11,08 & 12,70 & 13,58 & 2,65 & 2,16 \\
\hline Municípios de Porte I & 1217767 & 1565820 & 1762832 & 6,40 & 7,08 & 7,03 & 2,31 & 1,33 \\
\hline Demais Municípios & 11015508 & 11323851 & 11414815 & 57,88 & 51,17 & 45,53 & 0,25 & 0,09 \\
\hline Centro-Oeste & 6801666 & 9418581 & 11611491 & 100,00 & 100,00 & 100,00 & 3,00 & 2,35 \\
\hline RM's & 1337419 & 1963935 & 2935510 & 19,66 & 20,85 & 25,28 & 3,55 & 4,57 \\
\hline AGUNM & 286227 & 564771 & 697340 & 4,21 & 6,00 & 6,01 & 6,37 & 2,37 \\
\hline Municípios de Porte Médio & 544053 & 885046 & 1093816 & 8,00 & 9,40 & 9,42 & 4,52 & 2,38 \\
\hline Demais Municípios & 4633967 & 6004829 & 6884825 & 68,13 & 63,76 & 59,29 & 2,38 & 1,53 \\
\hline BRASIL & 119002706 & 146816455 & 169544443 & 100,00 & 100,00 & 100,00 & 1,93 & 1,61 \\
\hline RM's & 40561170 & 51566033 & 61549587 & 34,08 & 35,12 & 36,30 & 2,21 & 1,99 \\
\hline AGUNM & 11519524 & 16670309 & 20353120 & 9,68 & 11,35 & 12,00 & 3,42 & 2,24 \\
\hline Municípios de Porte Médio & 10892419 & 14821581 & 18043223 & 9,15 & 10,10 & 10,64 & 2,84 & 2,21 \\
\hline Demais Municípios & 56029593 & 63758532 & 69598513 & 47,08 & 43,43 & 41,05 & 1,18 & 0,98 \\
\hline
\end{tabular}

Fonte: FIBGE, Censos Demográficos de 1980, 1991 e 2000; Contagem da População de 1996.

(*) As Regiões Metropolitanas contemplam todas as áreas criadas oficialmente e não apenas as adotadas no estudo IPEA/IBGE/NESUR-UNICAMP (2000). Já as Aglomerações Urbanas Não-Metropolitanas (AGUNM) baseiam-se no referido estudo

Cadernos do Leste

Artigos Cientificos

Belo Horizonte, Edição Especial, 2000 a 2008 
Assim, considerando as regiões metropolitanas, as aglomerações urbanas, os municípios de porte médio e as demais localidades - aqui chamadas de municípios nãoprimazes - pode-se notar que, no contexto nacional, as áreas metropolitanas concentram $36,3 \%$ da população total, as aglomerações urbanas não-metropolitanas e os municípios de porte médio aglutinam outros $22,6 \%$ da população, cabendo finalmente aos demais municípios a expressiva proporção de $41,1 \%$ da população total.

Isto indica a existência de desconcentração populacional no interior da rede urbana já que o País encontra-se amplamente urbanizado, exibindo Grau de Urbanização de cerca de 80\% -, com áreas fora das metrópoles capazes de absorver e reter população. Essas novas configurações urbanas vêm sendo marcadas, no entanto, por um processo de incorporação de áreas que se expandem no contexto de dinâmicas regionais ou locais especificas, conformando novas espacialidades do processo de urbanização brasileira. As aglomerações urbanas não-metropolitanas, por exemplo, contribuem, de um lado, para amortecer o crescimento urbano das metrópoles e, de outro lado, introduzem maior adensamento na rede urbana que, por sua vez, também passa a desempenhar importante papel no processo de redistribuição interna da população brasileira.

No ano 2000, havia no País 31 Aglomerações Urbanas Não-Metropolitanas, das quais 14 na Região Sudeste (Tabela 6). Os Municípios de Porte Médio fora das concentrações metropolitanas e de aglomerações chegaram a integralizar 61 localidades, destacando-se a importante participação desses municípios em regiões tão contrastantes em termos socioeconômicos, como o Nordeste (com 12 centros urbanos dessa ordem) e o Sul (com 10).

Cadernos do Leste

Artigos Cientificos

Belo Horizonte, Edição Especial, 2000 a 2008 


\section{Tabela 6}

Distribuição dos Centros Urbanos segundo Grandes Regiões em 2000

\begin{tabular}{l|r|r|r}
\hline $\begin{array}{l}\text { Grandes } \\
\text { Regiões }\end{array}$ & Metrópoles & $\begin{array}{c}\text { Aglomerações } \\
\text { Urbanas Não- } \\
\text { Metropolitanas }\end{array}$ & $\begin{array}{l}\text { Municípios } \\
\text { de Porte } \\
\text { Médio }\end{array}$ \\
\hline Norte & 1 & 0 & 11 \\
Nordeste & 4 & 9 & 12 \\
Sudeste & 6 & 14 & 23 \\
Sul & 5 & 7 & 10 \\
Centro-Oeste & 2 & 1 & 5 \\
Brasil & 18 & 31 & 61 \\
\hline
\end{tabular}

Fonte: Censos Demográficos de 2000

Em distintos contextos regionais, desde as metrópoles até os municípios NãoPrimazes, as taxas médias de crescimento populacional apresentaram-se positivas, conforme mostrava a Tabela 5, podendo, de fato, estar indicando uma maior retenção de população em variadas categorias de tamanho de municípios. Enquanto o Brasil metropolitano cresceu, no período 1991-2000, a uma taxa de 2,0\% a.a., as Aglomerações Urbanas Não-Metropolitanas cresceram a 2,24\% a.a., e os Municípios de Porte Médio a 2,16\% a.a., enquanto os NãoPrimazes, a quase 1,00\% a.a.

Essas taxas de crescimento foram bastante díspares, consideradas as Grandes Regiões. Focalizando-se a Região Norte, verifica-se que os Municípios Não-Primazes experimentaram a mais alta taxa entre as Grandes Regiões, 2,55\% a.a., número esse superior a até mesmo os relativos às metrópoles do Sudeste. Moura e Moreira (1998) chamam a atenção para o surgimento, no sistema urbano da Região, de municípios pequenos não-metropolitanos, a internalizar o que se tem denominado de "nova ruralidade"; tais localidades começam a ter acesso a serviços básicos e vêm se tornando centros de prestação de serviços ao nível local e mesmo sub-regional. Contudo, a configuração urbana ${ }^{24}$ da Região é marcada pela centralidade dos principais núcleos urbanos de Belém e Manaus (NESUR-IE/UNICAMP, 1998a; Moura e

\footnotetext{
${ }^{24}$ As análises referentes a rede urbana de cada uma das regiões beneficiam-se dos resultados do projeto "Caracterização e Tendências da Rede Urbana no Brasil" - IPEA/IBGE/ NESUR - IE/UNICAMP, entre dezembro de 1997 e novembro de 1998.

Cadernos do Leste

Artigos Cientificos

Belo Horizonte, Edição Especial, 2000 a 2008
} 
Moreira, 1998), embora as demais capitais estaduais venham também se destacando como pólos urbanos, com taxas de crescimento superiores a 3\% a.a., entre 1991-2000. Soma-se, então, a esses centros regionais as espacialidades da "nova ruralidade".

Na Região Nordeste, as regiões metropolitanas têm registrado taxas de crescimento próximas às Aglomerações Urbanas Não-Metropolitanas e às dos Municípios de Porte Médio (em torno de 2\% a.a. nos anos 90). Embora, os Municípios Não-Primazes respondessem por 61,0\% da população regional, em 2000, tal participação tem declinado, em favor de municípios que compõem as concentrações urbanas.

Essa concentração metropolitana no Nordeste reflete a própria dinâmica da urbanização regional. Os anos 80 aceleraram o processo de esvaziamento das áreas rurais nordestinas, quando, pela primeira vez nos últimos cinquenta anos, sua população rural diminuiu em números absolutos (de 17.245.514 de habitantes, em 1980, para 16.721.621, em 1991, chegando a 15.575.505, em 1996). Certamente, parte dessa população que emigrou de áreas rurais no período 1980-1996, foi absorvida no urbano da própria região, mormente nas áreas metropolitanas. Note-se que a taxa de crescimento da população urbana do Nordeste foi de 2,5\% a.a. entre 1991-1996, claramente superior à média nacional (2,1\% a.a.).

O recente dinamismo econômico em determinadas localidades do Nordeste, especialmente voltado para o complexo petroquímico de Camaçari, o polo têxtil de Fortaleza, o complexo mineral-metalúrgico de Carajás, o polo agroindustrial de Petrolina/Juazeiro, as áreas de agricultura moderna de grãos, as atividades turísticas e a produção de frutas para exportação ampliaram e diversificaram a estrutura econômica nordestina (Araújo, 1995; Pacheco, 1998), contribuindo inclusive para a expansão de atividades terciárias e propiciando a retenção e o retorno da população.

$\mathrm{Na}$ Região Sudeste, o menor crescimento metropolitano é o mais eloquente no conjunto das Grandes Regiões. As taxas de crescimento da população mostram-se relativamente próximas nas distintas categorias urbanas da Tabela 5, em torno de 1,51\% a.a. e 1,73\% a.a., não obstante a predominância do crescimento urbano não-metropolitano. Aspectos de difusão mais homogênea da urbanização constituem uma forte característica da

Cadernos do Leste

Artigos Cientificos

Belo Horizonte, Edição Especial, 2000 a 2008 
Região, algo que se associa ao surgimento de novas aglomerações urbanas e à densificação de áreas urbanas estrategicamente localizadas na rede de cidades.

A histórica concentração das atividades econômicas no Sudeste, especialmente em São Paulo, Rio de Janeiro e parte de Minas Gerais, tornou esta região a mais urbanizada do País (89,3\% de sua população vivia em áreas urbanas em 1996), sediando as três mais importantes metrópoles nacionais e o maior volume de população urbana, 59.825.958 habitantes em 1996. Nesse contexto, a rede urbana redesenha-se atribuindo novos papéis às antigas metrópoles.

No caso da Região Sul, o crescimento dos municípios metropolitanos (3,13\% a.a., no período 1991-2000) foi maior que todas as demais categorias, em especial se comparados com os Municípios Não-Primazes (0,09\% a.a., no mesmo período). Seu recente dinamismo econômico vem deixando reflexos no processo de urbanização regional, com a formação de pólos de desenvolvimento nos três estados, a exemplo do calçadista no Vale dos Sinos, da indústria mecânica na Grande Porto Alegre e no nordeste de Santa Catarina; do petroquímico de Triunfo, no Rio Grande do Sul; da refinaria de Araucária; e do distrito industrial de Curitiba, no Paraná (Pacheco, 1998).

A recuperação demográfica da região, em especial do Paraná, e a nova dinâmica econômica tiveram rebatimentos espaciais diversificados que se expressaram no sistema urbano sulino. De acordo com os resultados da pesquisa NESUR-IE/UNICAMP e IPEA (1998e:107) “a principal característica da rede urbana sulina é a conjugação de um número cada vez maior de municípios populosos em aglomerações urbanas - espaços qualificados como áreas de concentração tanto populacional quanto da atividade econômica", que, na verdade, serviram para frear os crescentes deslocamentos populacionais para as áreas metropolitanas tradicionais da região.

A maior expressão da nova dinâmica socioespacial do processo de urbanização em curso no Brasil pode ser ainda observada na Região Centro-Oeste, com a formação do Entorno de Brasília $^{25}$, e a configuração da metropolização regional. A partir dos anos 90, o

${ }^{25}$ Trata-se da Região Integrada de Desenvolvimento do Distrito Federal e Entorno (RIDE); o Decreto $\mathrm{n}^{\mathrm{o}} 2710$ de 04/08/1998 regulamentou a Lei Complementar $n^{\circ} 94$ e autorizou o Poder Executivo a criar a Região (CODEPLAN/GDF).

Cadernos do Leste

Artigos Cientificos

Belo Horizonte, Edição Especial, 2000 a 2008 
incremento populacional deste conjunto de municípios passou a responder por 53,5\% do total regional, proporção que era de 40,1\%, no período 1981-1991; a taxa de crescimento das metrópoles do Centro Oeste (Brasília e Goiânia) alcançou 4,57\% a.a., entre 1991-2000; a mais elevada da morfologia da rede urbana brasileira. Marcada pela expansão, modernização e urbanização da fronteira agrícola, o Centro-Oeste experimentou um processo de desruralização de sua população já nos anos 70, quando, em contrapartida, sua população urbana alcançou a taxa de 7,6\% a.a., superior até a da Região Norte no mesmo período (6,6\% a.a.). No período 1980-1991, o ritmo de crescimento da população urbana diminuiu, embora sua taxa de crescimento urbano tenha se situado acima da média nacional (4,3\% a.a. contra 3,0\% a.a., respectivamente). Essa tendência prosseguiu nos primeiros anos da década de 90, quando o Centro-Oeste apresentou uma taxa de crescimento da população urbana em torno de 3,0\% a.a. e o Brasil de 2,1\% a.a.

"Esse generalizado movimento em direção às cidades é característico da dinâmica econômica da região: a prevalência de uma agricultura produtora de commodities, altamente capitalizada e tecnificada. Além de não necessitar de trabalho vivo em grande escala, conforma a propriedade e o uso da terra segundo sua lógica de valoração, esvaziando o campo e provocando um afluxo migratório em direção aos centros urbanos de maior porte". (NESUR-IE/UNICAMP, 1998f:59)

A nova dinamização das atividades agropecuárias, voltadas para o complexo grãos/carne, atrela o setor terciário e a atividade industrial a esse dinamismo com reflexos importantes na configuração urbana regional, chegando o Centro-Oeste a registrar 86\% de sua população em localidades urbanas, em 2000; perdendo apenas para a Região Sudeste (90,5\%) em termos de grau de urbanização.

\section{2- CONSIDERAÇÕES FINAIS}

As migrações internas e a urbanização andaram juntas na maior parte do Brasil do século XX. São fatores chaves que explicam em grande medida a redistribuição da população no espaço e o desenvolvimento de uma rede de localidades densas, nas quais desdobram-se os processos econômicos e sociais dos últimos 50 anos e das próximas décadas.

Cadernos do Leste

Artigos Científicos

Belo Horizonte, Edição Especial, 2000 a 2008 
A dinâmica migratória mantém estreitos vínculos com as transformações deflagradas pela expansão econômica e pode, tanto exprimir a espacialização dessa expansão, assim como sinalizar para novas conformações na distribuição territorial da população brasileira, evidenciando aspectos inéditos relativos aos desequilíbrios regionais, que escapariam à pura lógica de observação das atividades econômicas. Muitos migrantes podem estar fazendo movimentos de retorno à suas regiões de origem, desvinculados dos fluxos econômicos diretamente associados aos investimentos produtivos urbano-industriais. Outros, após alguma experiência em grandes centros urbanos, podem estar procurando áreas rurais, ou municípios de características rurais, atraídos por novas oportunidades pouco percebidas nos últimos anos pelas autoridades de governo.

Em termos demográficos, as cidades quase sempre mostram níveis de fecundidade mais baixos que no campo. Assim, a migração manifesta-se como uma componente chave que tanto explica sua expansão concentracionista, como a desconcentração espacial da população. Recorde-se que grande parte da urbanização brasileira foi resultado de saídas maciças de população de áreas rurais estagnadas e/ou semi-estagnadas para centros urbanos em expansão. Todavia, com a predominância das migrações de tipo urbano-urbano sobre as de tipo rural-urbano, gradativamente, reconfiguram-se as áreas de atração na rede de cidades, inclusive em face do próprio crescimento de centros urbanos regionais de tipo metropolitano, como Belo Horizonte, Porto Alegre, Fortaleza, Brasília, entre outros. Assim, os fluxos de pessoas e mercadorias passavam a se disseminar por mais alternativas locacionais, distintas das metrópoles nacionais (São Paulo e Rio de Janeiro).

Vimos que o País experimentou expressivas mudanças entre 1950 e 1960, alicerçadas pelo avanço da urbanização e pelo expressivo aumento dos movimentos migratórios de tipo campo-cidade, mantendo ritmos de expansão elevados durante os anos 60 e 70, à época do chamado 'milagre econômico'. Todavia, começava a delinear-se uma nova etapa no processo de ocupação territorial, com a maturação do desenvolvimento urbano-industrial e a redução dos fluxos de origem rural, embora ainda se reforçasse o padrão de concentração da população em cidades de tamanho cada vez maior. Nesse momento, o debate sublinhava os problemas associados à chamada 'macrocefalia urbana' e formação de 'megalópoles', Cadernos do Leste 
certamente em face do notável crescimento das configurações metropolitanas na década de 70 .

Contudo, desde então multiplicam-se os estudos procurando compreender os novos rumos que a urbanização brasileira vem assumindo. As discussões sobre a interiorização do desenvolvimento econômico, desmetropolização, desconcentração industrial e populacional a partir de São Paulo e Rio de Janeiro encontram interlocutores com posições discrepantes. Alguns assinalando o papel indutor dos investimentos públicos e privados disseminadores de externalidades e efeitos multiplicadores diversos, ainda que restritos a um determinado ‘campo aglomerativo' que não ultrapassa o Sudeste. Outros salientando os efeitos históricos inerciais no que tange às instalações e investimentos produtivos já implantados que impõem resistências à alterações no padrão locacional concentrador, impedindo assim a desconcentração econômico-espacial. Outros ainda, entendendo que há em curso um processo de desconcentração-concentrada, que se desenvolve em espaços seletivos, relativamente bem equipados, especialmente em centros urbanos de porte médio que ganharam maior visibilidade nos últimos 20 anos.

Certamente o debate ainda prosseguirá por um bom tempo, provavelmente ganhando mais consistência à medida que novos estudos forem se acumulando. Nesse sentido, merece atenção as várias análises que vêm se multiplicando nos últimos anos, buscando enfrentar questões demográficas, econômicas e socioespaciais que se refiram, por exemplo a: a) importância quantitativa e substantiva dos movimentos migratórios envolvendo áreas metropolitanas, aglomerações urbanas não-metropolitanas e localidades não-primazes; b) fluxos migratórios de retorno e suas características socioeconômicas atuais comparadas com os demais migrantes internos; c) mudanças no padrão de desenvolvimento a partir do arrefecimento do processo de desconcentração industrial, crise econômica e energética e aumento da pobreza e exclusão em grandes metrópoles; d) possíveis dinâmicas reconcentradoras de investimentos e instalações urbanas, provavelmente de novo tipo, baseadas em setores de alta tecnologia; e) metamorfose da rede urbana brasileira, emoldurando diferentes vínculos de interdependência e complementaridade entre cidades densas e de localizações territoriais estratégicas.

Cadernos do Leste

Artigos Cientificos

Belo Horizonte, Edição Especial, 2000 a 2008 
$\mathrm{Na}$ verdade, ao se considerar as cinco Grandes Regiões brasileiras, verifica-se que, o Sudeste tanto exibe o menor crescimento metropolitano, quanto a mais densa rede urbana e o maior contingente de população urbana do País, testemunhando o surgimento de novas aglomerações urbanas, sediando importantes metrópoles nacionais. Não é de se surpreender que a influência do dinamismo econômico sudestino alcance grande parte do território nacional, sobretudo as regiões fronteiriças do Sul e Centro-Oeste.

No Sul, se é fato a existência de uma rede urbana relativamente antiga e estável, dotada de muitas cidades de tamanho pequeno e intermediário, é também notável a recente expansão de suas áreas metropolitanas ao lado da consolidação de pólos de desenvolvimento, no litoral e em sua fronteira oeste, certamente recebendo a influência do estado de São Paulo. Situações semelhantes também ocorrem em boa porção Centro-Oeste, onde novas articulações dão dinamismo ao sul e sudoeste do Mato Grosso do Sul e Goiás, à sub-região de Brasília e entorno, Goiânia e Anápolis, todas ostentando taxas de crescimento urbano bem acima das médias nacionais. A Região Norte, embora mais distante dos eixos mais dinâmicos do País, exibe também expressiva expansão da urbanização, caracterizando-se como uma importante área de atração de migrantes, tanto em função da presença dos maiores centros, Belém e Manaus, quanto das capitais estaduais e outras áreas urbanas que vêm se estruturando articuladas com o Centro-Oeste e o Nordeste.

Finalmente, com respeito à Região Nordeste, tradicional área de evasão populacional, cabe observar que suas metrópoles e aglomerações urbanas não-metropolitanas também têm registrado taxas de crescimento superiores à média nacional na última década, provavelmente refletindo o esvaziamento de suas áreas rurais, a própria dinâmica da urbanização regional em espaços econômicos bem determinadas e até os fluxos de retorno à região.

Certamente uma pergunta recorrente e sem resposta clara até o momento é se a reestruturação produtiva tem privilegiado espaços urbanos dinâmicos e tradicionais que podem implicar reconcentração industrial. De todo modo, uma reestruturação sócio-espacial se situaria nos moldes da concentração que ocorreu entre os anos 1930 e 1970; afinal as taxas de crescimento da população metropolitana nacional apresentaram decréscimos consideráveis

Cadernos do Leste

Artigos Cientificos

Belo Horizonte, Edição Especial, 2000 a 2008 
nos anos 80 e 90, e os dados do Censo de 2000, indicam continuidade da desaceleração do crescimento metropolitano, sobretudo em São Paulo e Rio de Janeiro.

Por fim, uma última palavra sobre a importância dos Censos Demográficos brasileiros, a mais decisiva fonte de dados sobre migrações internas. Desde o Censo Demográfico de 1970 tornou-se possível obter informações mais detalhadas sobre os lugares de origem dos migrantes e a procedência urbana ou rural. Esse Censo, inclusive, deve ter estimulado o surgimento de muitos trabalhos sobre migrações internas levados a efeito à época. O crescimento exacerbado dos grandes centros urbanos preocupava as autoridades e instituições de governo, o que propiciou a produção de informações de qualidade e a realização de vários trabalhos que vieram salientar a importância das migrações internas, destacando-a enquanto mecanismo básico de formação dos mercados de trabalho urbano, e como um processo que realimentava e caracterizava o intenso crescimento das cidades. ${ }^{26}$

Em 1980, o IBGE realiza um Censo com um plano amostral que cobria 25\% da população brasileira, introduzindo inovações e avanços metodológicos no estudo das migrações. Incorpora-se um quesito que nomeava o município e a Unidade de Federação de residência anterior dos migrantes com menos de 10 anos de residência no município atual, e um outro sobre a migração intramunicipal. Além disso, perguntas anteriormente feitas somente aos não-naturais são estendidas a toda a população amostrada, o que permitiu a análise da migração de retorno. ${ }^{27}$

Assim, a partir do momento em que se tornou disponível essa fonte de dados, ocorre, na segunda metade dos anos 80, um revigoramento dos estudos migratórios, com o surgimento de diversos artigos, relatórios de pesquisa e teses defendidas sobre o tema, tais como os desenvolvidos pela UNICAMP. São trabalhos reunidos na forma de artigos e livros

\footnotetext{
${ }^{26}$ Entre os muitos trabalhos realizados na década de 70 que se tornaram referências obrigatórias sobre o tema, merecem ser mencionados pelo menos os seguintes: Balan J. (1973), Faissol, S. (1973), Mata, M. (1973), Martins J.S. (1975), Oliveira, O. Stern, C. (1971), Lopes (1974), Lopes, J.B., Patarra N.L. (1974), Graham, D.H., Hollanda, S.B.F (1980), Silva (1973), Singer (1976), Costa M. (1975), Castro, M.G., Fraenkel, L.M., Neto, E.T. (1976), Martine G., Peliano, J.C. (1978), Martine G. (1976), Faria (1976), Moura H. (1980) e Sawyer (1984).

${ }^{27}$ Contudo com a não publicação dos dados "sobre não-naturais da UF por tempo de residência e lugar de domicílio anterior não se pode mais calcular a imigração de cada UF", em relação às demais, assim como a emigração (Carvalho, 1985:38/39).
}

Cadernos do Leste

Artigos Cientificos

Belo Horizonte, Edição Especial, 2000 a 2008 
editados pela própria universidade, publicados em Anais de Encontros da Associação Brasileira de Estudos Populacionais (ABEP) e da Associação Nacional de Planejamento Urbano e Regional (ANPUR), nos Anais dos Encontros Nacionais sobre Migrações Internas, na Revista Brasileira de Estudos Populacionais, entre outros. Além disso, cite-se o grande número de monografias, dissertações, teses e pesquisas elaboradas por graduandos, pósgraduandos e professores-pesquisadores do CEDEPLAR, NEPO/UNICAMP, Fundação Joaquim Nabuco, Fundação IBGE, ou publicações em jornais de circulação nacional e periódicos internacionais, a exemplo dos trabalhos sobre os novos fluxos migratórios no estado de São Paulo elaborados por Bogus (1990), Cunha (1987, 1990 e 1994), Perillo (1990). Sobre aspectos metodológicos e fontes censitárias de informação devem ser citados Carvalho (1985), Cunha (1987), Machado, CC, Hakkert, R. (1988), Carvalho e Machado (1992). Além destes cabe mencionar as participações de Matos (1994), Salim (1992), Bremaeker (1992) e Sales (1994), assim como algumas teses tratando especificamente desta temática, tais como Salim (1993), Cunha (1994) e, abordando estritamente o caso mineiro, Rigotti (1994) e Matos $(1995)^{28}$.

No Censo de 1991, houve a redução do tamanho da amostra para 10\% e foi introduzido um quesito que permite localizar o lugar de residência do migrante em 1986, a chamada variável de "data fixa", o que representou outro avanço metodológico. Os quesitos incorporados tornavam possível identificar as principais áreas de emissão e recepção de migrantes e localizar os fluxos migratórios em diferentes momentos no tempo. Já o Censo de 2000, além de manter os quesitos que permitem estimar a migração em intervalos qüinqüenais, reintroduz o quesito presente no Censo de 1980, relativo à chamada "migração pendular", aquela que envolve a população que reside em municípios diferentes daqueles onde trabalha ou estuda. Todavia, houve o sacrifício da variável "última etapa" (nome do município de procedência entre 1991 e 2000), o que irá penalizar os estudos que trabalham

\footnotetext{
${ }^{28}$ Trabalho que analisa a emigração e imigração em Belo Horizonte com base nos dados do Censo de 1980, mostrando a importância dos fluxos de saída da Capital mineira para diversos municípios do Estado e, em especial para alguns municípios conurbados da região metropolitana.Com os dados do Censo de 1991 mantevese confirmado o processo de desconcentração populacional em Minas Gerais, notadamente em subespaços sobre a influência de Belo Horizonte, e em sub-regiões dinâmicas do Sul e Triângulo.
}

Cadernos do Leste

Artigos Cientificos

Belo Horizonte, Edição Especial, 2000 a 2008 
com pequenas áreas, como os municípios, mas requerem tamanhos significativos de amostras relativas a população migrante buscando, ao mesmo tempo, explorar cruzamentos com outras variáveis do questionário.

De toda a forma, o Censo Demográfico é, sem dúvida, um dos mais completos do mundo, constitui a principal fonte de dados para a realização de estudos sobre as migrações internas no Brasil, e ainda estamos longe de esgotar as possibilidades de tratamento e análise dos dados censitários existentes, especialmente se explorando procedimentos comparativos.

Através de determinados cruzamentos entre as variáveis dos Censos Demográficos pode-se conhecer tanto os principais centros urbanos de emissão e recepção de migrantes, quanto averiguar as características demográficas, econômicas e sociais que possuíam tais populações à data do Censo. Este é um conhecimento que vem ganhando importância e se generalizando há pouco mais de 10 ou 15 anos nas Ciências Sociais. O aumento de trabalhos sobre o tema, juntamente com a produção de sínteses elucidativas, concentrando-se sobre as tendências predominantes nos movimentos migratórios, são contribuições necessárias ao entendimento mais atual das dinâmicas sócio-espaciais que recobrem os novos padrões de distribuição da população brasileira. As migrações representam hoje uma das áreas de maior interesse no interior da demografia e das Ciências Sociais em geral. Os trabalhos se multiplicam, tanto nos encontros bianuais da Associação Brasileira de Estudos Populacionais (ABEP), como nos "Encontros Nacionais sobre Migrações Internas" promovidos desde 1997.

A exploração dos dados censitários vem permitindo afirmar que o processo de redistribuição espacial da população parece apontar para diferentes manifestações da desconcentração espacial da população, não obstante a diversidade de ritmos e intensidades da expansão demográfica conforme a geografia econômica dos lugares, as crises estruturais intersetoriais e as dinâmicas macroeconômicas de médio e longo prazo.

Cadernos do Leste

Artigos Cientificos

Belo Horizonte, Edição Especial, 2000 a 2008 


\section{REFERÊNCIAS BIBLIOGRÁFICAS}

AMARANTE, Luis A., BONDIOLI, Paulo. A apropriação regional da renda nacional no Brasil; 1975-85. São Paulo em Perspectiva, revista da fundação SEADE, São Paulo, v.1, n.3, out/dez, 1987.

ARAÚJO, T.M.B. (1995). Nordeste, Nordeste: que Nordeste? In: Affonso, R. e Barros Silva, P. L. (orgs). Desigualdades Regionais e Desenvolvimento (Federalismo no Brasil). São Paulo: FUNDAP/ ED. UNESP, p. 125-156.

AZZONI, C. Indústria e Reversão da Polarização no Brasil. Ensaios Econômicos-IPE/USP, São Paulo, n.58, 1986.

BAENINGER, R. (1999). Região, Metrópole e Interior: Espaços Ganhadores e Espaços Perdedores nas Migrações Recentes no Brasil - 1980/1996. Tese de Doutorado. IFCH/UNICAMP, Campinas.

BALÁN, J. Migraciones e desarrollo capitalista en el Brasil: ensaio de interpretación históricocomparativa. Migración y Desarrollo, CLACSO, 1974.

BENKO, G. e LIPIETZ, A. O Novo Debate Regional: posições em confronto. In: Benko, G. e Lipietz, A (org.). As Regiões Ganhadoras - Distritos e Redes: os novos paradigmas da geografia econômica. Celta Editora, Oeiras, 1994 (p.3-15).

BENKO, G. Economia, Espaço e Globalização: na aurora do século XXI. Editora Hucitec, São Paulo, 1996.

BILSBORROW, R. E. (org.). Migration, urbanization and development: new directions and issues. New York : UNFPA/Kluwer, 1996.

BRITO, F. População, espaço e economia numa perspectiva histórica: o caso brasileiro. Belo Horizonte : CEDEPLAR/UFMG-Faculdade de Ciências Econômicas, 1997. (Tese de Doutorado)

CAMARANO, A.A. (1998). Movimentos Migratórios Recentes na Região Nordeste. . In: Encontro Nacional sobre Migração, Curitiba, Anais..., ABEP/IPARDES, p. 189-208.

CANO, W. (1988), coord, A Interiorização do Desenvolvimento Econômico no Estado de São Paulo (1920-1980). São Paulo: Fundação SEADE, v.1. a v. 3 (Coleção Economia Paulista).

CANO, W. Algumas implicações espaciais da Terceira Revolução Industrial no Brasil. In:

Cadernos do Leste

Artigos Científicos

Belo Horizonte, Edição Especial, 2000 a 2008 
GONÇALVES, M. F. (org). O novo Brasil urbano. Porto Alegre : Editora Mercado Aberto, $1995 \mathrm{a}$.

CANO, W. Auge e inflexão da desconcentração econômica regional. In: AFFONSO, R, SILVA, P. L. B. A federação em perspectiva: ensaios selecionados. São Paulo: Fundap, 1995b. p.399-416.

CANO, W. Migrações, desenvolvimento e crise no Brasil. Campinas : Instituto de Economia/UNICAMP, 1996. (mimeo)

CANO, W. Raízes da Concentração Industrial em São Paulo, 2 ed. São Paulo: TA Queiroz, 1977.

CARVAlHO, J. A. M., RIGOTTI, J. I. Análise das metodologias de mensuração das migrações. In: ENCONTRO NACIONAL SOBRE MIGRAÇÃO, 1998, Curitiba. Anais ... Curitiba: IPARDES/ABEP, 1998.

CASTELLS, M. The Informational City, Information Technology, economic restructuring and the urban-regional process. Oxford, Basil Blackwell, 1989.

CELADE (Centro Latinoamericano de Demografia). Dinâmica de la población en las grandes ciudades en América Latina y Caribe. Documentos Docentes, Santiago de Chile, 1994.

COUTINHO, L. O desenvolvimento urbano no contexto da mudança tecnológica. . In: Gonçalves, M.F. (org). O Novo Brasil Urbano. Editora Mercado Aberto, Porto Alegre, 1995.

COUTINHO, Luciano. 'O desenvolvimento urbano no contexto da mudança tecnológica". In: GONÇALVES, M.F. (Org.). O novo Brasil urbano. Mercado Aberto, Porto Alegre, 1995, pp.: 41-62.

CUNHA, J. M. P. (coord.). Projeto "Mobilidade e redistribuição espacial da população no Estado de São Paulo: características recentes, padrões e impactos no processo de urbanização". Campinas : NEPO/UNICAMP, 1999. 273p. (Relatório Final)

CUNHA, J.M.. (Des) continuidades no padrão demográfico do fluxo São Paulo/Bahia no período 1990/1991: qual o efeito da crise. In: ENCONTRO NACIONAL DE ESTUDOS DE POPULACIONAIS, 11., 1998, Caxambu. Anais ... Caxambu : ABEP, 1998.

DEDDECA, C.S., BRANDÃO, S.M.C. Crise, transformações estruturais e mercado de trabalho. Campinas : CEDE/UNICAMP, 1992. (mimeo)

DINIZ e CROCCO, M. Reestructuración Económica e Impacto Regional: el nuevo mapa de la indústria brasileña. In: Mattos, C.; Nicolás e Botero, D. Globalización y Territótio impactos e perspectivas. Fondo de Cultura Económica. Chile, 1998.

Cadernos do Leste

Artigos Científicos

Belo Horizonte, Edição Especial, 2000 a 2008 
DINIZ, C.C. Desenvolvimento poligonal no Brasil; nem desconcentração, nem contínua polarização. Nova Economia - Revista do Departamento de Ciências Econômicas da UFMG, vol 31, n.11, Belo Horizonte, 1993.

DINIZ, C.C. Dinâmica regional recente e suas perspectivas. In: AFFONSO, R., SILVA, P. L. B. A federação em perspectiva: ensaios selecionados. São Paulo: Fundap, 1995. p.417-429.

EBANKS, E.G. Determinantes Socioeconómicos de la Migración Interna. CELADE, Santiago de Chile, 1993.

FARIA, V. Cinqüenta anos de urbanização no Brasil: tendências e perspectivas. Novos Estudos CEBRAP 29, São Paulo, p.98-119, mar.1991.

FARIA, V. Divisão Social do trabalho, espacialização e crescimento urbano: o caso da macrometrópole Paulista. In: Anais do II Encontro Nacional de Estudos Populacionais, São Paulo: ABEP, 1980.

FARIA, V. O processo de urbanização no Brasil: algumas notas para seu estudo e interpretação. In: Anais do I Encontro Nacional de Estudos Populacionais. São Paulo: ABEP, 1978.

FARIA,V. Desenvolvimento, Urbanizaçãoe Mudanças na Estrutura do Emprego: a experiência brasileira dos últimos 30 anos. In: Sorj , B. e Almeida, M.H. Sociedade e Política no Brasil Pós-64. São Paulo: Editora Brasiliense, 1983.

FUNDAÇÃO IBGE. Contagem Populacional de 1996. Rio de Janeiro, 1997.

FUNDAÇÃO IBGE. Pesquisa Nacional por Amostra de Domicílio. Rio de Janeiro, PNAD, 1995.

FUNDAÇÃO IBGE/DPE/DPIS/DICAD/DEMOG. Movimentos migratórios segundo o Censo Demográfico de 1991 e Contagem da População de 1996. Rio de Janeiro : IBGE, 1997. (mimeo)

GOTTDIENER, M A Produção Social do Espaço. EDUSP, São Paulo, 1993.

GOTTDIENER, M. A teoria da crise e a reestruturação sócio-espacial: o caso dos Estados Unidos. In: Valladares, L. e Preteceille, E. (coord.). Reestruturação Urbana: tendências e desafios. Nobel/IUPERJ, São Paulo, 1990. (p.59-78)

Cadernos do Leste

Artigos Cientificos

Belo Horizonte, Edição Especial, 2000 a 2008 
GRAHAM, D. e BUARQUE DE HOLLANDA, F.S. Migration, regional and urban growth and development in Brazil: a selective analyses of the historical record, 1972-1970. São Paulo, IPE/USP, 1971.

GREENWOOD, Michael. Migrações internas nos Estados Unidos; uma revisão da literatura. In: MOURA, A. M. (Coord). Migração interna; textos selecionados. Fortaleza: Banco do Nordeste do Brasil, 1980, p. 733-77. 1980.

GUIMARÃES, E. e LEME, H. (1997). Caracterização histórica e configuração espacial da estrutura produtiva do Centro Oeste. In: NEPO/UNICAMP. TEXTOS NEPO 33, Campinas.

HADDAD, Paulo. Economia Regional; teorias e métodos de análise, Recife, Banco do Nordeste do lBrasil, 1980.

HARVEY, D. Condição Pós-Moderna. Editora Loyola, São Paulo, 1992.

IPEA/IBGE/NESUR-UNICAMP. Características e Tendências da Rede Urbana no Brasil. Instituto de Economia-UNICAMP, 2000.

KATZMAN, Martin T. Urbanização no Brasil a partir de 1945. In: BACHA, E., KLEIN, H. S. A transição incompleta; Brasil desde 1945. Rio de Janeiro: Paz e Terra, 1986, p.177-229.

LATTES, A. E. Population distribution in Latin America: is there a trend towards population deconcentration? In: Population, distribution and migration. New York : United Nations, 1998.

LOPES, J.R. e PATARRA, N.L. Redistribuição regional e rural-urbana da população brasileira. Estudos sobre a população brasileira. Cadernos CEBRAP, 20, São Paulo, 1975.

LOPES, J.R.B. Desenvolvimento e migração: uma abordagem histórico-estrutural. Estudos CEBRAP, São Paulo, n.6, 1973.

MAGALHÃES, M. Movimentos migratórios na Região Sul: novas tendências. In: ENCONTRO NACIONAL SOBRE MIGRAÇÃO, 1998, Curitiba. Anais ... Curitiba : IPARDES/ABEP, 1998.

MARTINE, G. A evolução espacial da população brasileira. In:AFFONSO, R. B. A., SILVA, P. L. B. (orgs.). Desigualdades regionais e desenvolvimento (Federalismo no Brasil). São Paulo: FUNDAP/Ed. UNESP, 1995. p.61-91.

MARTINE, G. As migrações de origem rural no Brasil: uma perspectiva histórica. História e População - Estudos sobre a América Latina. ABEP/IUSSP/CELADE. São Paulo, 1990.

Cadernos do Leste

Artigos Cientificos

Belo Horizonte, Edição Especial, 2000 a 2008 
MARTINE, G. e CAMARGO, L. Crescimento e distribuição da população brasileira: tendências recentes. Revista Brasileira de Estudos de População, Campinas, ABEP, 1(2), p.99143, jan./dez.1984.

MARTINE, G. e CAMARGO, L. Crescimento e distribuição da população brasileira: tendências recentes. Revista Brasileira de Estudos de População, Campinas, ABEP, 1(2), p.99143, jan./dez.1984.

MARTINE, G. e PELIANO, J.C. Migrantes no mercado de trabalho metropolitano. Série Estudos para o Planejamento, Brasília, Ipea, 1976.

MARTINE, G. Migração e Metropolização. Revista São Paulo em Perspectiva, São Paulo, Fundação SEADE, 1987.

MARTINE, G., CAMARANO, A.A., NEUPERT, R. e BELTRÃO, K. A urbanização no Brasil: retrospectiva, componentes e perspectivas. In: ENCONTRO NACIONAL DE ESTUDOS POPULACIONAIS 6, 1988, Olinda. Anais... Brasilia: ABEP, 1988.

MARTINE, G.. A redistribuição espacial da população brasileira durante a década de 80 . Textos para Discussão 329, Brasília, IPEA, 1994. 43p.

MARTINE,G. Processos recentes de concentração e desconcentração urbana no Brasil: determinantes e implicações. Documento de Trabalho 11, Brasília, Instituto SPN, 1992. 29p.

MATOS, C. de "Capital, Población y Territorio". Seminário Distribución y Movilidad Territorial de la Población y Desarrollo Humano. Fundación Bariloche/CENEP/PROLAP. Bariloche, Argentina, maio, 1994.

MATOS, R.E.S, Dinâmica migratória e desconcentração da população na macrorregião de Belo Horizonte. Belo Horizonte. CEDEPLAR (tese de doutorado), 1995.

MATOS, R.E.S, “Questões teóricas acerca dos processos de concentração e desconcentração da população no espaço”. In: Revista Brasileira de Estudos Populacionais. São Paulo, 1995, p. 35-58.

MERRICK, T. e GRAHAM, D. Population and economic developmente in Brazil, 1800 to the present. Baltimore, Johns Hopkins University Press, 1979.

MOTTA, Diana M. e AJARA, Cesar. "Rede urbana brasileira-hierarquia das cidades". Curso de Gestão Urbana e de Cidade EG/FJP-WBI-PBH-ESAF-IPEA, ago, 1999

MOURA, H. M. e MOREIRA, M.M. (1998). As Migrações na Região Norte em Período Recente: uma abordagem preliminar. In: Encontro Nacional sobre Migração, Curitiba, Anais..., ABEP/IPARDES, p. 138-188.

Cadernos do Leste

Artigos Cientificos

Belo Horizonte, Edição Especial, 2000 a 2008 
NEGRI, B. Concentração e desconcentração industrial em São Paulo (1880-1990). Campinas: Ed. UNICAMP, 1996.

NEGRI, B. e PACHECO, C. A . Mudança Tecnológica e Desenvolvimento regional nos Anos 90: da interiorização do desenvolvimento à nova dimensão espacial da indústria paulista (Relatório Final). Projeto Desenvolvimento Tecnológico e Competitividade da Indústria Brasileira. SCTDE/FECAMP/UNICAMP/IE, Campinas, 1993.

NÚCLEO DE ECONOMIA SOCIAL, URBANA E REGIONAL - NESURIE/UNICAMP (1998 a). Caracterização e Tendências da Rede Urbana no Brasil - Estudos Regionais. Relatório 6. Campinas, outubro (mimeo).

PACHECO, C. (1993). Evolução Recente da Urbanização e da Questão regional no Brasil: implicações econômicas para a dinâmica demográfica. Anais da IV Conferencia Latinoamericana de Población. Ciudad de México.

PACHECO, C. A . Fragmentação da nação. Campinas : Instituto de Economia/UNICAMP, 1998.

PACHECO, C. A. e PATARRA, N. L. Movimentos Migratórios nos Anos 80: novos padrões? In: Encontro Nacional sobre Migração. Anais..., Curitiba, 1997.

PACHECO, C. e PATARRA, N. L. Movimentos migratórios anos 80: novos padrões? In: ENCONTRO NACIONAL SOBRE MIGRAÇÃO, 1998. Anais ... Curitiba : ABEP/IPARDES, 1998.

PACHECO, C.A. e PATARRA, N. L. Tendências da Urbanização e do Crescimento Populacional Brasileiro: População em Idade Escolar. Instituto de Economia/UNICAMP, 2000.

PACHECO,C. (1992). Os Aglomerados Urbanos de São Paulo: as novas realidades demográficas e ocupacionais da urbanização paulista. Relatório de Pesquisa. Terciarização e Precarização da Estrutura Ocupacional nos Anos 80. Projeto Urbanização e Metropolização no Estado de São Paulo. SPG/FECAMP.

PACHECO,C. A. Fragmentação da Nação. Instituto de Economia/UNICAMP, 1998. PANIZZI, W. Prefácio do Livro O Novo Brasil Urbano. Editora Mercado Aberto, Porto Alegre,1995.

PATARRA, N.L. et al . Migrações, Dinâmica Urbana e Condições de Vida. Instituto de Economia-UNICAMP, 1997.

Cadernos do Leste

Artigos Cientificos

Belo Horizonte, Edição Especial, 2000 a 2008 
PIORE, M. e SABEL. C. The Second Industrial Divide. Nova York, Basic Books, 1984.

PORCHMANN, Marcio. "São Paulo: a capital e o trabalho". Revista República, São Paulo, n. 52, fev. 2001

PRETECEILLE, E. e VALLADARES, L. Introdução. In: Valladares, L. e Preteceille, E. (coord.). Reestruturação Urbana: tendências e desafios. Nobel/IUPERJ, São Paulo, 1990. (p.7-13)

REDWOOD III, John. Reversion de polarizacion, ciudades secundarias y eficiencia en el desarrollo nacional: una vison teorica aplicada al Brsil contemoraneo. Revista Latinoamericana de Estudios Urbanos Regionales, Santiago, vol 11, n.32, dez. 1984

RICHARDSON, H. Economia Regional, Teoria da Localização, Estrutura Urbana e Crescimento Regional. Zahar Editores, Rio de Janeiro, 1975.

RIGOTTI, J. I. R , CARVALHO, J. A. M. As migrações na grande Região Centro-Leste. In: ENCONTRO NACIONAL SOBRE MIGRAÇÃO, 1997, Curitiba. Anais ... Curitiba : ABEP/IPARDES, 1997. p.67-90.

SANTOS, M. (1997) Técnica, Espaço e Tempo: globalização e meio técnico-científicoinformacional. 3 ed. Hucitec: São Paulo.

SANTOS, M. A metrópole: modernização, involução e segmentação. In: Valladares, L. e Preteceille, E. (coord.). Reestruturação Urbana: tendências e desafios. Nobel/IUPERJ, São Paulo, 1990. (p.183-191)

SANTOS, M. et al (1994). Território, Globalização e Fragmentação. Hucitec: São Paulo.

SANTOS, M. Técnica, Espaço, Tempo: Globalização e Meio Técnico-Científico Informacional. Editora Hucitec, São Paulo, $3^{\text {a }}$ edição, 1997.

SASSEN, S The Mobility of Labor and Capital. Cambridge University Press, Cambridge, 1988

SINGER, P. Economia Política da Urbanização. São Paulo: HUCITEC, 1973.

STORPER, M. A industrialização e a questão regional no Terceiro Mundo. . In: Valladares, L. e Preteceille, E. (coord.). Reestruturação Urbana: tendências e desafios. Nobel/IUPERJ, São Paulo, 1990. (p.120-147)

TASCHNER, S. P., BOGUS, L. M. M. Mobilidade espacial da população brasileira: aspectos e tendências. Revista Brasileira de Estudos de População, São Paulo, 3(2), jul./dez.1986.

Cadernos do Leste

Artigos Científicos

Belo Horizonte, Edição Especial, 2000 a 2008 
TOWNROE, P.M e KEEN, D.. Polarization reversal in the state of São Paulo, Brazil.

REGIONAL STUDIES; Journal of the Regional Studies Association, Cambridge. V. 18, n. 1, Feb, 1984.

VALLADARES, L. e PRETECEILLE, E. (coord.). Reestruturação Urbana: tendências e desafios. Nobel/IUPERJ, São Paulo, 1990.

VÉRAS, M.P. Entre o Local e o Global: políticas urbanas, espaços e sujeitos da cidade mundial. Trabalho apresentado na XX Encontro Anual da ANPOCS, Caxambu, outubro, 1996.

VILLA, M., RODRIGUEZ, J. Dinámica sociodemografica de las metrópolis latinoamericanas. In: Grandes ciudades de América Latina: dos capítulos. Documentos Docentes, Santiago de Chile, Centro Latinoamericano de Demografia-CELADE, Naciones Unidas-FNUAP, 1994. 